\title{
Investigating the Transition from Elevated Multicellular Convection to Surface-Based Supercells during the Tornado Outbreak of 24 August 2016 Using a WRF Model Simulation
}

\author{
KEVIN GRAY AND JEFFREY FRAME \\ Department of Atmospheric Sciences, University of Illinois at Urbana-Champaign, Urbana, Illinois
}

(Manuscript received 20 December 2018, in final form 5 June 2019)

\begin{abstract}
On 24 August 2016, a tornado outbreak impacted Indiana, Ohio, and Ontario with 26 confirmed tornadoes. Elevated multicellular convection developed into surface-based supercells that produced several tornadoes, particularly near a differential heating boundary. This convective mode transition is of particular interest owing to its relatively rare occurrence. A WRF Model simulation accurately captures the environment and storm evolution during this outbreak. Trajectory analyses indicate that the multicellular updrafts were initially elevated. Since nearly all of the vertical wind shear was confined to the lowest $1 \mathrm{~km}$, significant rotation did not develop via tilting of horizontal vorticity until the storms began ingesting near-surface air. Nearsurface vertical wind shear decreased outside of cloud cover owing to vertical mixing, while it was preserved under the anvil, allowing for large values of $0-1-\mathrm{km}$ storm-relative helicity to persist north of a differential heating boundary. Analysis of the perturbation pressure field from the WRF Model output indicates that the development of relatively large nonlinear vertical perturbation pressure gradients coincided with when nearsurface air began to enter the updrafts, resulting in upward accelerations in the lowest $2 \mathrm{~km}$, below the level of maximum rotation. In strengthening updrafts, upward-directed buoyancy perturbation pressure accelerations may have offset the downward-directed nonlinear perturbation pressure accelerations above the level of maximum rotation, allowing the updrafts to intensify further.
\end{abstract}

\section{Introduction}

\section{a. Event overview}

A tornado outbreak caught many meteorologists by surprise on 24 August 2016 when storms produced 26 confirmed tornadoes across portions of Indiana, Ohio, and Ontario. Many convection-allowing models initialized that morning did not depict discrete storms or significant updraft helicity swaths across the affected area, but instead indicated that a line of storms would form, contributing to this challenging forecast. This event is also of interest because while a leading line of elevated storms dissipated as it entered Indiana (Fig. 1a; cluster 1), a second line persisted and transitioned from disorganized elevated multicellular convection (Fig. 1a; cluster 2) to three discrete supercells in Indiana after 1800 UTC (Fig. 1b), all of which produced significant tornadoes (rated EF-2 or greater on the enhanced Fujita scale). Additional

\footnotetext{
Corresponding author: Kevin Gray, kevintg2@illinois.edu
}

supercells developed behind the initial supercells after 2000 UTC (Fig. 1b), and many of these storms also produced tornadoes. The transition of the elevated multicellular convection into the first round of surfacebased tornadic supercells is unusual and of particular interest. There are several studies on how surface-based storms become elevated (e.g., Parker 2008; French and Parker 2010; Geerts et al. 2017) and how supercells grow upscale into multicellular complexes (e.g., Bluestein and Weisman 2000; Finley et al. 2001; Gropp and Davenport 2018), but the transition from elevated to surface-based convection is relatively unexplored, especially the transition from elevated multicellular to surface-based supercellular convection.

\section{b. Background and motivation}

A case study by Burgess and Curran (1985) summarizes a solid line of storms becoming a broken line of supercells in Oklahoma on 26 April 1984. The authors mention that this evolution took forecasters by surprise, much like the tornado outbreak of 24 August 2016. On 26 April 1984, isolated storms initiated along a north-south-oriented 


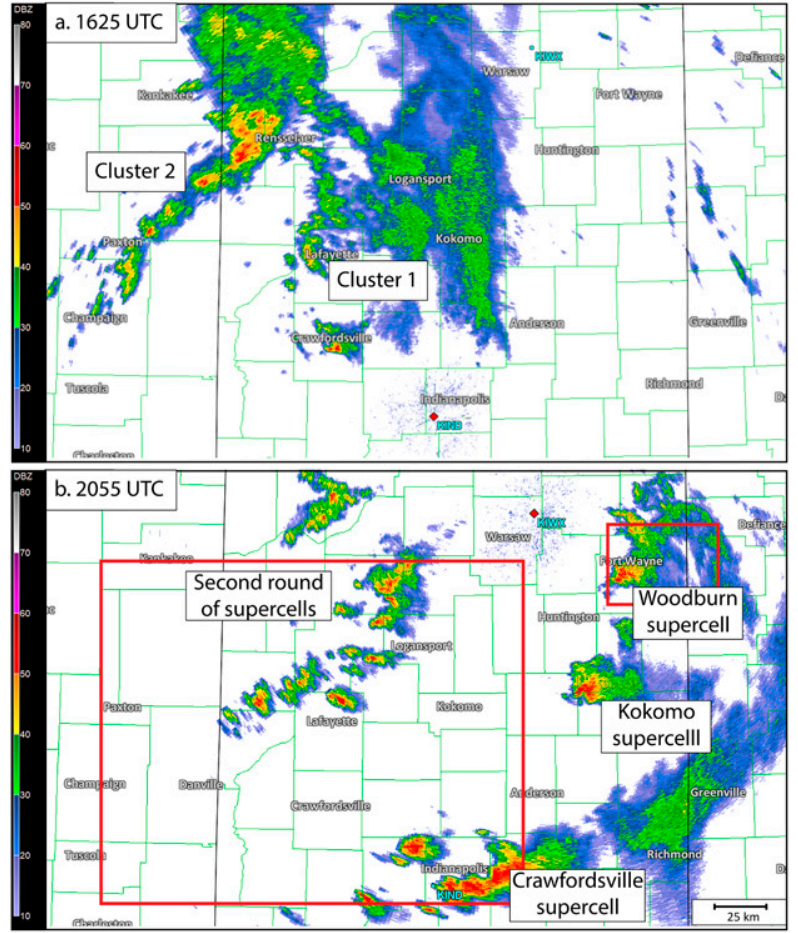

FIG. 1. Radar reflectivity (dBZ) from the (a) Indianapolis, IN (KIND), WSR-88D at 1625 UTC and (b) North Webster, IN (KIWX), WSR-88D at 2055 UTC. The two storm clusters discussed in the text are labeled in (a); the three primary supercells and second round of supercells are labeled in (b). The western red box in (b) is the domain of Fig. 5, and the eastern red box is the domain of Figs. 6e and $6 \mathrm{f}$.

dryline and were overtaken by a cold front around sunset, resulting in a solid line of storms. Overnight, the line broke into discrete tornadic supercells. Their analysis indicates that this transition to supercells was made possible by an increase in hodograph curvature after sunset owing to an approaching shortwave trough and the onset of the nocturnal low-level jet. This occurred in tandem with increasing warm air advection above the surface, allowing for the redevelopment of a capping inversion, such that only dominant rotating updrafts within the line survived to realize the increased storm-relative helicity (SRH). On 24 August 2016, however, there was not a dryline or any synoptic fronts present in the region affected by the outbreak and the transition to supercells occurred during the afternoon, not at night. A similar storm mode transition occurred along a cold front in North Carolina on 16 April 2011, but it appears that there is no investigation of this event in the formal literature. We are unaware of any other in-depth examinations of transitions from linear or multicellular convection to discrete supercells.

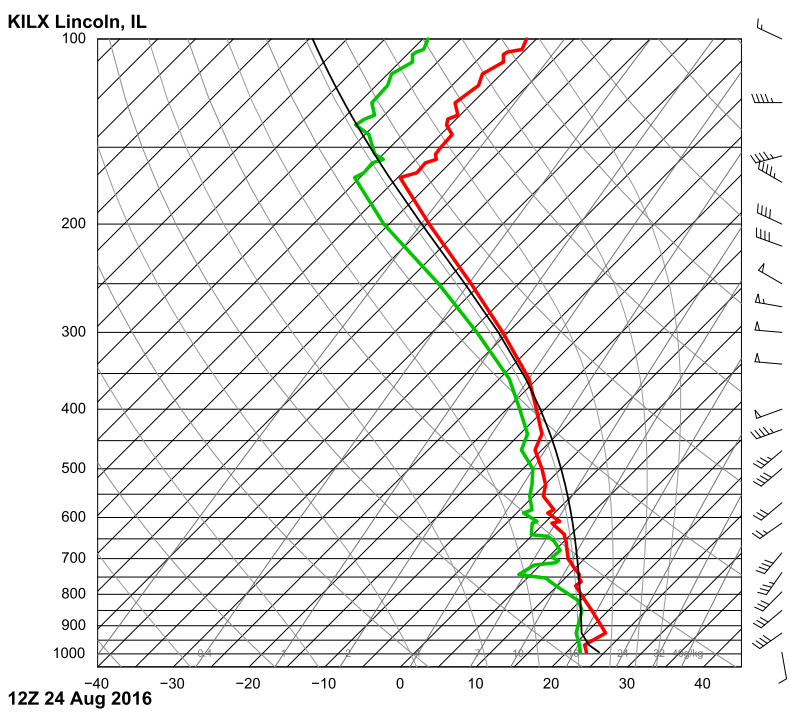

FIG. 2. The 1200 UTC sounding launched from Lincoln, IL. Winds are plotted in knots, with a flag $=50 \mathrm{kt}$, a barb $=10 \mathrm{kt}$, and a half barb $=5 \mathrm{kt}$.

An instance of elevated convection becoming a surface-based squall line on 13 June 2002 is documented by Marsham et al. (2011) and Trier et al. (2011). They found that the downdrafts from elevated nocturnal convection eventually penetrated a stable layer to reach the surface and form a cold pool, which lifted surface air to its level of free convection and allowed the storms to become surface based. Hane et al. $(2003,2008)$ also investigated the climatology of transitioning elevated nocturnal mesoscale convective systems (MCSs) and their propensity to dissipate in the morning hours. They found that systems that move from west to east are less likely to dissipate than systems moving from northwest to southeast, though a physical reason could not be provided. The authors surmise that the faster storm motions of the MCSs from the west in their study may have provided better low-level convergence along the gust fronts.

The transition of disorganized elevated multicellular convection into discrete surface-based supercells on 24 August 2016 is simulated with the Weather Research and Forecasting (WRF) Model and the output is analyzed herein. We hypothesize that when the storms were elevated, they were relatively unorganized due to little shear above a low-level inversion layer (roughly $925 \mathrm{hPa}$ in Fig. 2). As diurnal destabilization progressed, the storms began to ingest strongly sheared near-surface air, permitting mesocyclone development. Cloud cover in the inflow region of these storms likely slowed surface heating, limited vertical mixing, and preserved 0-1-km SRH (Markowski et al. 1998a; Frame and Markowski 2010) ahead of the storms. It is demonstrated that as rotation developed within the 

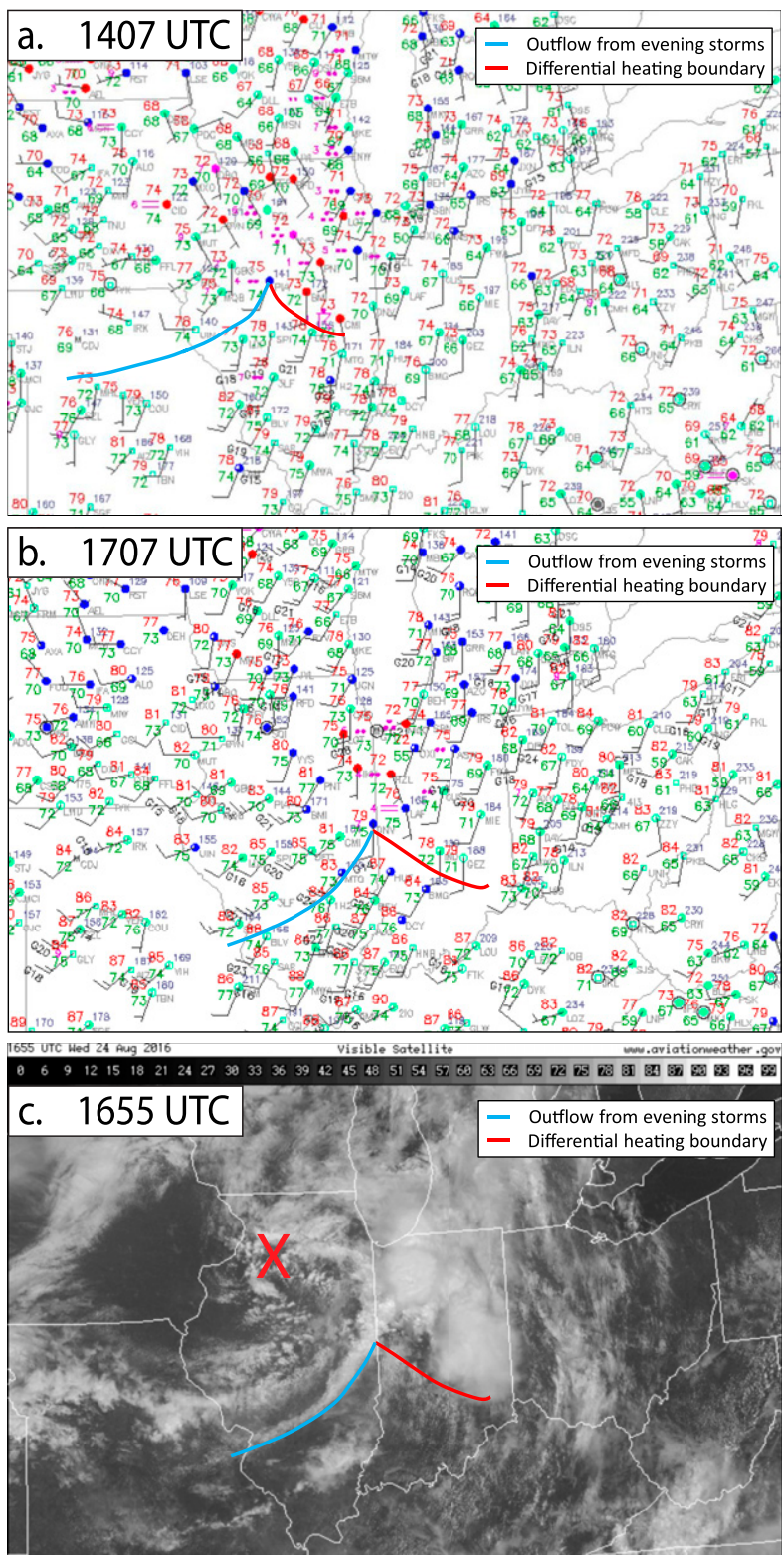

FIG. 3. Surface observations at (a) 1407 and (b) 1707 UTC. The blue line is the outflow boundary from the previous evening's storms, and the red line is the differential heating boundary. (c) Visible satellite at 1655 UTC. Colored lines are as in (a), and the red $\mathrm{X}$ indicates the MCV location.

updrafts, nonlinear dynamic pressure perturbations formed and allowed for upward accelerations, aiding in the ingestion of near-surface air. Section 2 contains an analysis of the synoptic and mesoscale environment and observed storm evolution on 24 August 2016. Section 3 presents the model configuration and methodology, including that for the trajectory analysis and perturbation pressure decomposition. Section 4 discusses the results, and section 5 presents the conclusions.
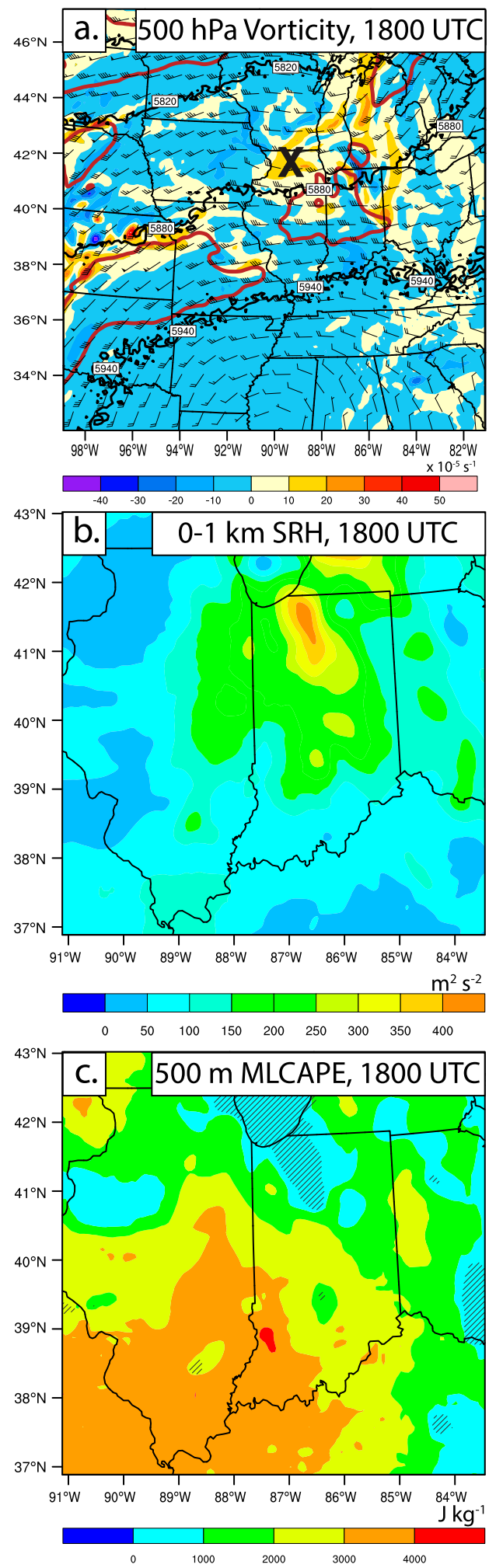

FIG. 4. The 1800 UTC RAP analysis of (a) 500-hPa height (black contour; $\mathrm{m}$ ), wind (barbs; $>40-\mathrm{kt}$ thick brown contour), relative vertical vorticity (shaded; $10^{-5} \mathrm{~s}^{-1}$ ), and MCV location (black X), (b) 0-1-km SRH (shaded; $\mathrm{m}^{2} \mathrm{~s}^{-2}$ ), and (c) 500-m MLCAPE (shaded; $\mathrm{J} \mathrm{kg}^{-1}$ ) and MLCIN (>25 $\mathrm{J} \mathrm{kg}^{-1}$ hatched). 


\section{Observed synoptic and mesoscale environment and storm evolution}

On the evening of 23 August 2016, a complex of storms developed over eastern Nebraska ahead of a cold front, spawning a mesoscale convective vortex (MCV) overnight. Widespread elevated convection developed ahead of this storm cluster in response to large-scale ascent, while the original complex dissipated over Iowa around 0900 UTC (not shown). The new convection organized into a line that moved eastward across Illinois that morning (Fig. 1a; cluster 1). Additional convection developed along the outflow boundary from the evening storm cluster around 1400 UTC in northern Illinois (Fig. 1a; cluster 2), yielding two lines of elevated storms.

\section{a. Synoptic environment and mesoanalysis}

The 1200 UTC 24 August sounding from Lincoln, Illinois (Fig. 2), depicts strong vertical wind shear between the surface and $925 \mathrm{hPa}$, where wind speeds increase from 10 to $40 \mathrm{kt}\left(1 \mathrm{kt} \approx 0.51 \mathrm{~m} \mathrm{~s}^{-1}\right)$ and veer from southeasterly to southwesterly, and only weak shear above $925 \mathrm{hPa}$. The outflow boundary from the evening storm complex exhibited a surface wind shift that separated southwesterly winds to its south from more westerly winds to its north (Figs. 3a,b) and a cloud line on visible satellite imagery (Fig. 3c). A differential heating boundary is marked by the southern edge of the cloud cover associated with cluster 1 and a shift from faster southwesterly surface winds outside of the cloud cover to slower, southerly winds and slightly cooler temperatures beneath the clouds (Figs. 3b,c). There were no sharp gust fronts or surging outflow associated with either cluster of storms in surface observations (Figs. 3a,b) or WSR-88D radial velocity data (not shown). After 1700 UTC, the differential heating boundary began to advance northeastward while the MCV continued to move eastward across northern Illinois.

By 1800 UTC, just before the first tornadoes occurred, the environment was favorable for the development of supercells and tornadoes per Rapid Refresh (RAP; Benjamin et al. 2016; Fig. 4) model analyses. At $500 \mathrm{hPa}$, the $\mathrm{MCV}$ had moved into northern Illinois and wind speeds greater than $40 \mathrm{kt}$ existed on its southeastern side near the Illinois/Indiana border (Fig. 4a). The 0-1-km SRH was greater than $100 \mathrm{~m}^{2} \mathrm{~s}^{-2}$ over most of Indiana (Fig. 4b), with values exceeding $200 \mathrm{~m}^{2} \mathrm{~s}^{-2}$ north of the differential heating boundary, favorable for the development of rotating updrafts. Plentiful instability [greater than $2000 \mathrm{~J} \mathrm{~kg}^{-1}$ 500-m mixed-layer CAPE (MLCAPE)] with little capping [less than $25 \mathrm{~J} \mathrm{~kg}^{-1}$ mixed-layer convective inhibition (MLCIN)] was present (Fig. 4c) with lifting condensation level (LCL) heights less than $750 \mathrm{~m}$ above ground level (AGL; not shown), providing a favorable environment for tornadoes. The development of tornadic supercells from cluster 2 is discussed below.

\section{b. Radar observations and storm evolution}

Cluster 2 was still multicellular at 1730 UTC (Fig. 5a) with only weak rotation within several cells at this time (Fig. 5b). Between 1730 and 1800 UTC, cluster 2 split into a southern group of cells (cluster 2A), and a northern line (cluster 2B; Fig. 5c). Small cells, each with strong updrafts evidenced by sharp reflectivity gradients and regions of convergence (not shown), continued to develop south of and merge with cluster $2 \mathrm{~A}$ during this period, and by 1800 UTC, there was one dominant area of rotation within cluster 2A (Figs. 5c,d). After a cell merger at 1832 UTC, rotation increased within the southernmost storm (Crawfordsville supercell; Figs. 6a,b) and it produced an EF-2 tornado from 1838 to 1848 UTC near Crawfordsville, Indiana (Fig. 7a; all tornado statistics are from Storm Data; NCDC 2016). This storm continued moving to the east-southeast, passing just north of Indianapolis where it produced another brief EF-0 tornado (Fig. 7a).

As the Crawfordsville supercell produced its first tornado, a storm on the southern end of cluster $2 \mathrm{~B}$ (Fig. 5c) began to develop rotation and a hook echo west of Kokomo, Indiana (Kokomo supercell; Figs. 6c,d). As the Kokomo supercell formed, the northeastern portion of cluster 2B separated from it just before 1850 UTC (cluster 2C; Fig. 6c). At 1911 UTC, a small cell west of the Kokomo supercell merged with it and rotation increased (Figs. 6c,d). The supercell produced an EF-3 tornado near Kokomo from 1920 to 1934 UTC (Fig. 7a). The Kokomo supercell also produced eight additional EF-0 and EF-1 tornadoes in far eastern Indiana and northwestern Ohio.

Cluster 2C continued moving east-northeastward as stronger convection formed on its southern flank through 2040 UTC (not shown). Rotation developed in one of these cells and it became a supercell by 2100 UTC (Woodburn supercell). This supercell produced an EF-3 tornado near Woodburn, Indiana, from 2127 to 2139 UTC (Figs. 6e,f and 7a) and four more tornadoes in northwestern Ohio. West of these three supercells, additional supercells formed in northcentral Indiana around 2000 UTC, several of which produced tornadoes as well. Sills et al. (2018) provide an analysis of the Ontario tornadoes (not shown in 

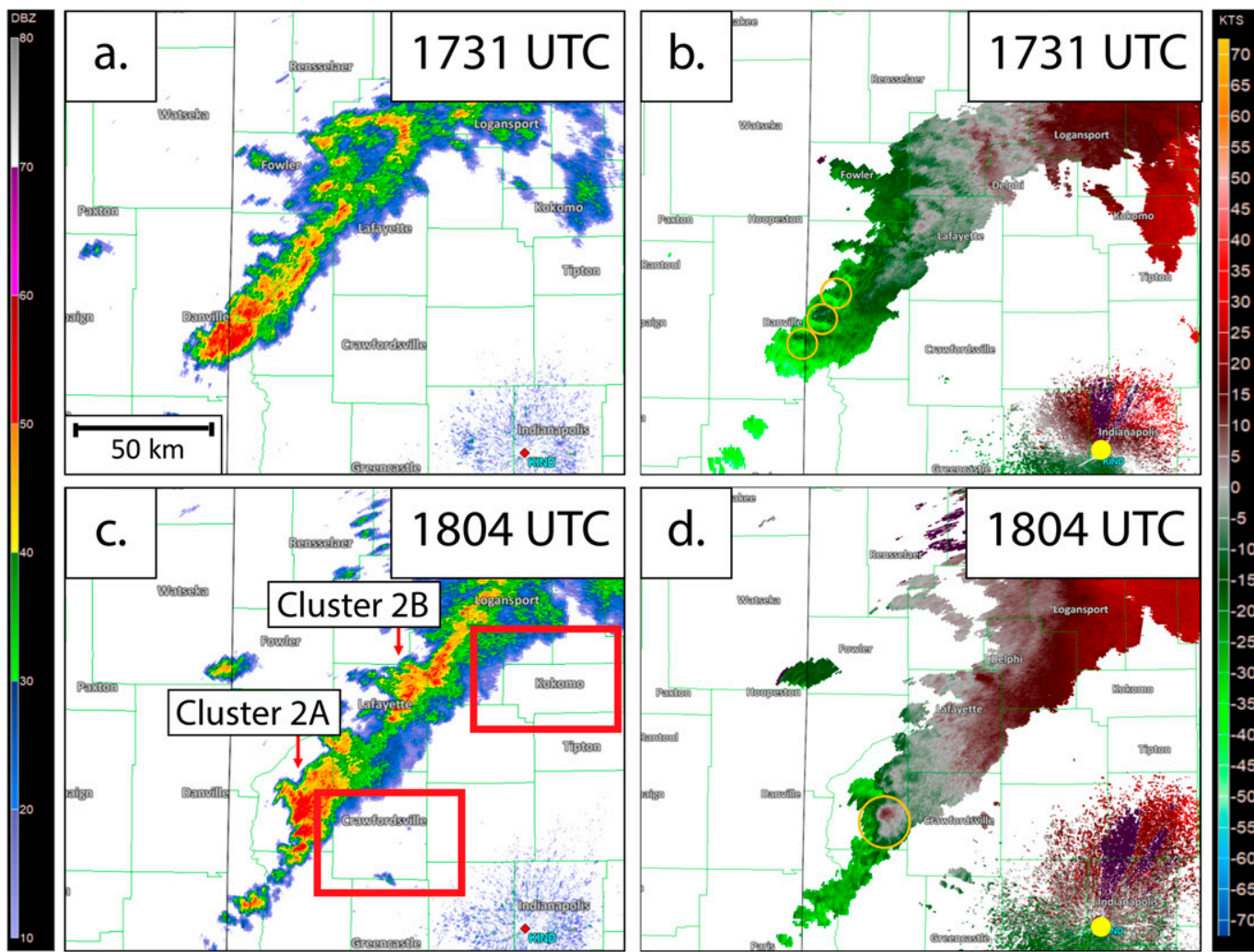

FIG. 5. Radar reflectivity (dBZ) from the Indianapolis, IN (KIND), WSR-88D at (a) 1731 and (c) 1804 UTC, and (b) radial velocity ( $\mathrm{kt}$; radar location at yellow dot) from the $1.4^{\circ}$ scan at $1731 \mathrm{UTC}$ and (d) from the $0.5^{\circ}$ scan at 1804 UTC. Areas of rotation are circled in (b) and (d). In (c), the boxed area including Crawfordsville, IN, is the domain of Figs. $6 \mathrm{a}$ and $6 \mathrm{~b}$ and the boxed area including Kokomo, IN, is the domain of Figs. $6 \mathrm{c}$ and $6 \mathrm{~d}$. The approximate domain of this figure is indicated in Fig. $1 \mathrm{~b}$.

Fig. 7a), and Frame and Gray (2018) present an indepth review of the observations.

The development of each supercell coincided with the northeastward movement of the differential heating boundary along the initial line of storms (Fig. 7). The production of the first significant tornado by each supercell occurred shortly after the storms acquired supercellular characteristics, and all significant tornadoes occurred in close proximity to this boundary. North of the differential heating boundary beneath the cloud cover, vertical mixing was weaker than to its south, which likely preserved vertical wind shear and horizontal vorticity near the surface (Figs. 2 and 4b), allowing for more relative vertical vorticity $\zeta$ to develop through tilting. Markowski et al. (1998b) and Rasmussen et al. (2000) found that the likelihood of tornadogenesis increases as a supercell travels from the warm to the cold side of a pre-existing mesoscale baroclinic boundary such as a differential heating boundary, further suggesting that the proximity of the supercells to the boundary was important for production of the significant tornadoes.

\section{Methodology}

\section{a. Model configuration}

The WRF-ARW model, version 3.8.1 (Skamarock et al. 2008), was used to simulate the 24 August 2016 storms. The outer domain measures $1695 \mathrm{~km} \times$ $1695 \mathrm{~km} \times 20 \mathrm{~km}$ with 60 vertical levels. The horizontal grid spacing of the outer domain is $3 \mathrm{~km}$, the vertical grid spacing is stretched from 50 to $250 \mathrm{~m}$ below $2 \mathrm{~km}$ and is $377.5 \mathrm{~m}$ above $2 \mathrm{~km}$, and the time step is $3 \mathrm{~s}$. A two-way nested inner domain with dimensions of $682 \mathrm{~km} \times$ $682 \mathrm{~km} \times 20 \mathrm{~km}$ and 60 vertical levels is centered over Illinois and Indiana with 1-km horizontal grid spacing, the same vertical grid as the outer domain, and a time step of $1 \mathrm{~s}$ (red box in Fig. 8a). Both domains utilize open boundary conditions. The model was initialized with the 0600 UTC 24 August 2016 12-km North American Mesoscale (NAM) model analysis, and the lateral boundary conditions of the outer domain were updated every six hours from NAM analyses. The inner domain was initialized at $1400 \mathrm{UTC}$, and the simulation terminated at 0000 UTC. 

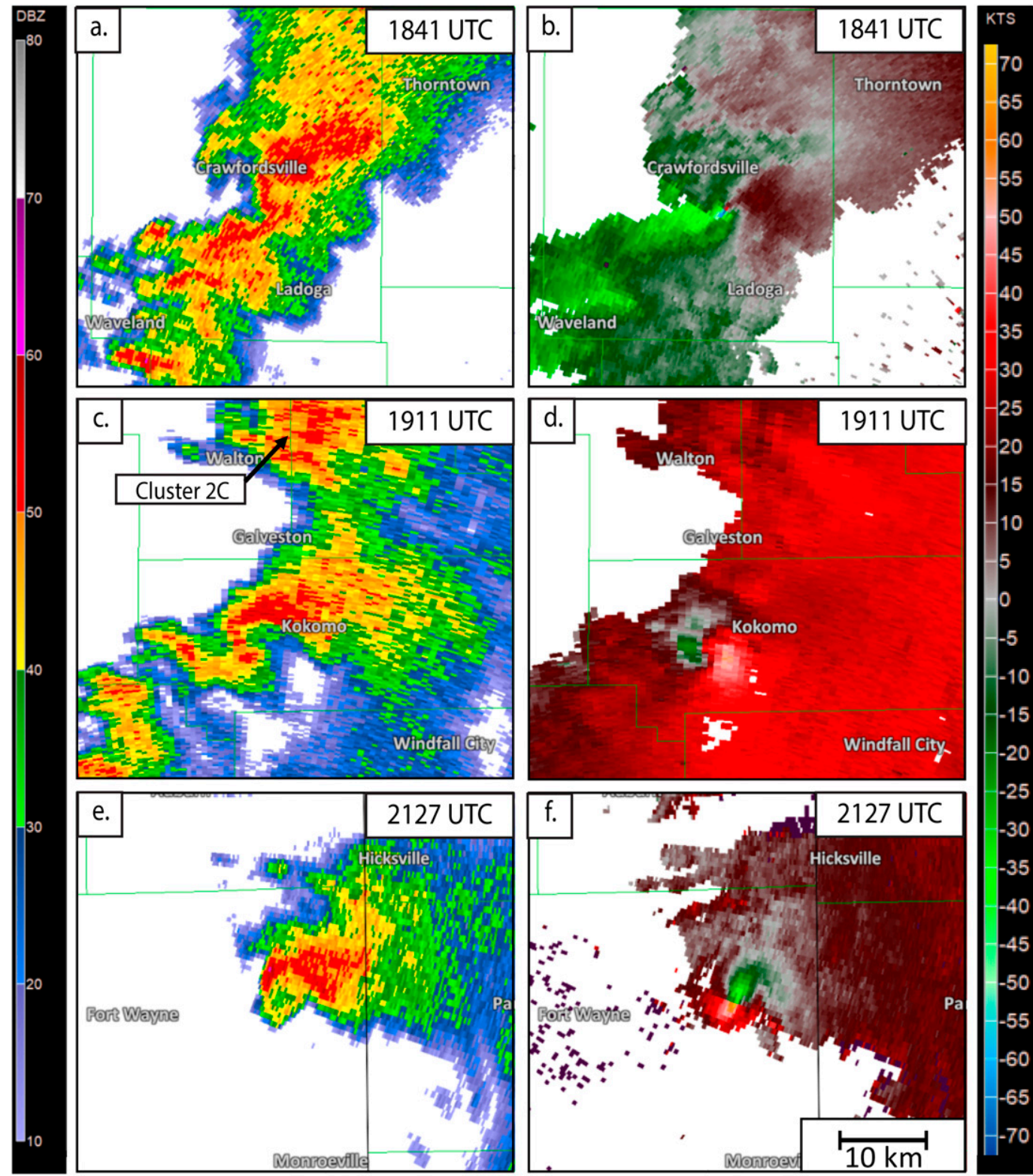

FIG. 6. (a) The $0.5^{\circ}$ radar reflectivity $(\mathrm{dBZ})$ and (b) radial velocity (kt) at $1841 \mathrm{UTC}$ from the Indianapolis, IN (KIND), WSR-88D depicting the Crawfordsville supercell. The radar site is southeast of the storm, and the domain is indicated in Fig. 5c. (c),(d) As in (a) and (b), but at 1911 UTC depicting the Kokomo supercell. The radar site is south of the storm, and the domain is indicated in Fig. 5c. (e),(f) As in (a) and (b), but from the North Webster, IN (KIWX), WSR-88D at 2127 UTC depicting the Woodburn supercell. The radar site is northwest of the storm, and the approximate domain of this figure is indicated in Fig. $1 \mathrm{~b}$.

The Milbrandt-Yau two-moment cloud microphysics parameterization was used for both domains (Milbrandt and Yau 2005). The Milbrandt-Yau scheme utilizes the collection efficiency described by Ziegler (1985) to parameterize raindrop breakup, where the default diameter at which collection efficiency begins to decrease from unity is $300 \mu \mathrm{m}$. For the simulation presented herein, this diameter was increased from the default of
300 to $450 \mu \mathrm{m}$, which is more representative of convective clouds. In a study that fitted microphysical observations of convective clouds to numerical model output, the diameter at which collection efficiency began decreasing from unity was $600 \mu \mathrm{m}$ (Verlinde and Cotton 1993). Furthermore, our $450-\mu \mathrm{m}$ diameter falls within the envelope of collection efficiencies investigated by Morrison and Milbrandt (2011, see their Fig. 18). 

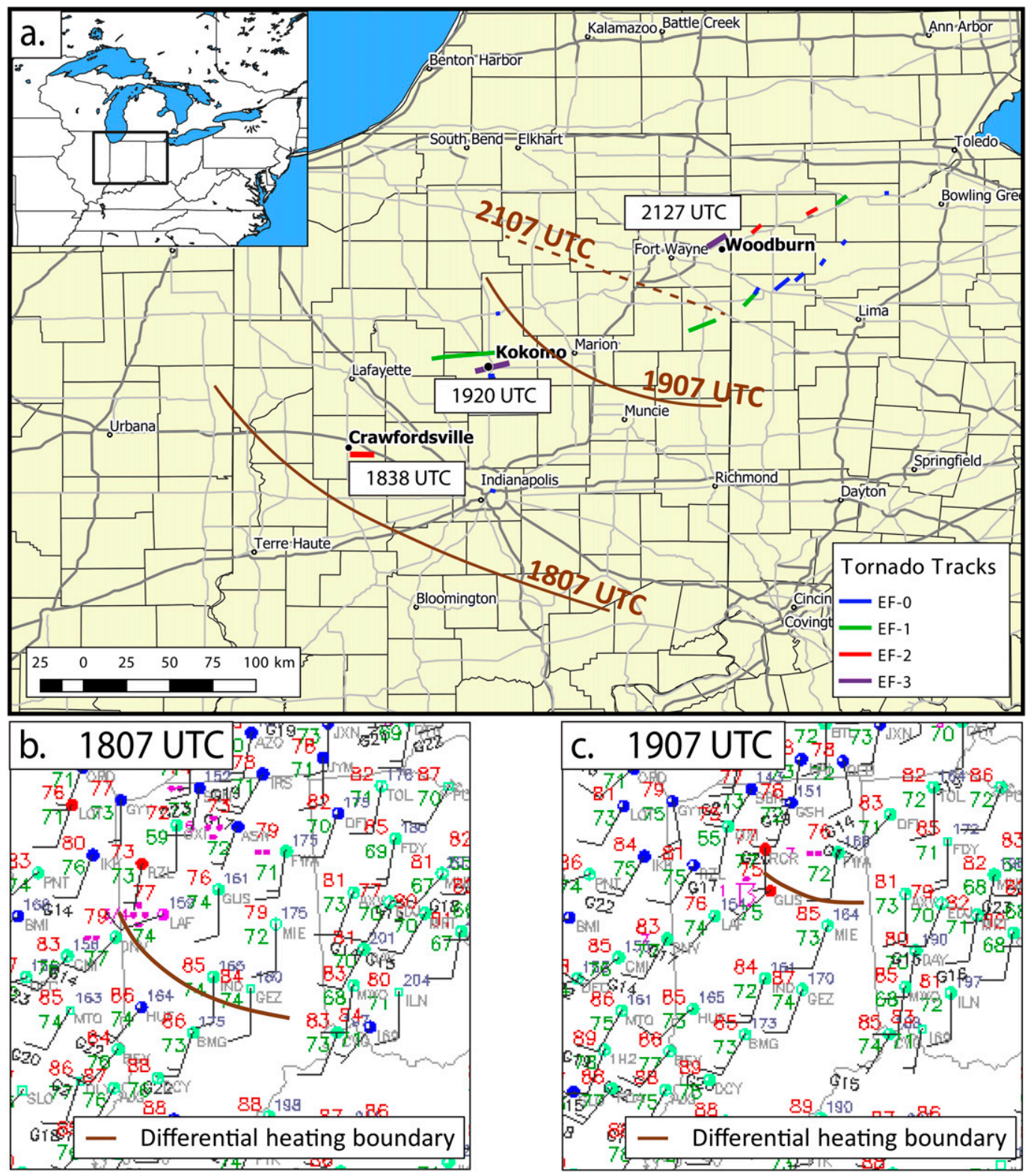

FIG. 7. (a) Tornado tracks from the 24 August 2016 outbreak (the two tornadoes in Ontario are not shown). Colors indicate enhanced Fujita scale rating. The towns nearest the three significant tornadoes in Indiana are labeled in bold text and the start time of each tornado is provided. Surface observations at (b) 1807 and (c) 1907 UTC. The solid brown lines represent the location of the differential heating boundary from surface and visible satellite observations. The dashed brown line in (a) is an estimate of the location of the differential heating boundary at 2107 UTC using only surface observations because widespread cloud cover at this time precluded the use of visible satellite imagery.

Simulations were performed using the default diameter of $300 \mu \mathrm{m}$ as well as $600 \mu \mathrm{m}$. The simulation using the $300-\mu \mathrm{m}$ diameter produced a bowing storm with too much outflow, while the storm in the simulation with the $600-\mu \mathrm{m}$ diameter was less outflow dominant, but developed farther north than was observed.
The Rapid Radiative Transfer Model for General Circulation Models was employed for both longwave and shortwave radiation (Mlawer et al. 1997; Iacono et al. 2000). The revised MM5 Monin-Obukhov surface layer scheme (Jiménez et al. 2012) and the Unified Noah land surface model (Livneh et al. 2011) were used. The MYNN 2.5-level TKE scheme 

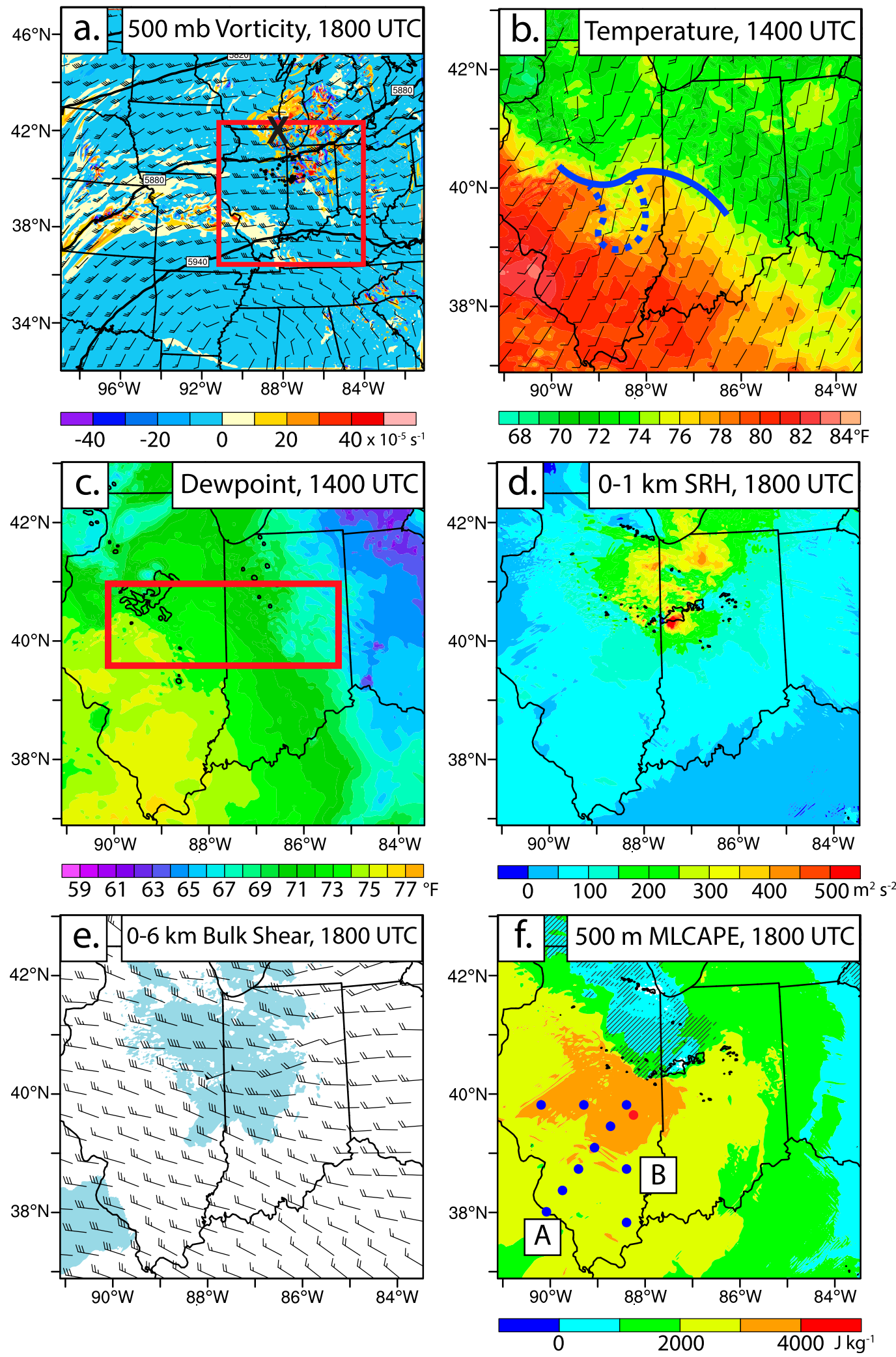

FIG. 8. (a) 500-hPa height (contoured; m MSL), winds (barbs; kt), relative vertical vorticity (shaded; $10^{-5} \mathrm{~s}^{-1}$ ), and MCV location (black X) at 1800 UTC from the outer domain. The red box is the inner domain. (b) Surface 
TABLE 1. Model physical and computational parameters. A dash for the inner domain indicates that the parameter is the same as that for the outer domain.

\begin{tabular}{|c|c|c|}
\hline Parameter & Outer domain & Inner domain \\
\hline Domain size & $1695 \mathrm{~km} \times 1695 \mathrm{~km} \times 20 \mathrm{~km}$ & $682 \mathrm{~km} \times 682 \mathrm{~km} \times 20 \mathrm{~km}$ \\
\hline Horizontal grid spacing & $3 \mathrm{~km}$ & $1 \mathrm{~km}$ \\
\hline Vertical grid spacing below $2 \mathrm{~km}$ & $50-250 \mathrm{~m}$ & - \\
\hline Vertical grid spacing above $2 \mathrm{~km}$ & $377.5 \mathrm{~m}$ & - \\
\hline Time step & $3 \mathrm{~s}$ & $1 \mathrm{~s}$ \\
\hline Boundary conditions & Open & - \\
\hline Initialization time & 0600 UTC 24 Aug 2016 & 1400 UTC 24 Aug 2016 \\
\hline Cloud microphysics & Milbrandt-Yau two-moment, $450-\mu \mathrm{m}$ breakup diameter & - \\
\hline Longwave and shortwave radiation & Rapid Radiative Transfer Model for GCMs & - \\
\hline Surface layer & Revised MM5 Monin-Obukhov & - \\
\hline Land surface & Unified Noah & - \\
\hline Boundary layer & MYNN 2.5-level TKE & - \\
\hline Turbulence closure & 2D Smagorinsky first-order closure & - \\
\hline Damping & Diffusive damping, $3000 \mathrm{~m}$ from model top & - \\
\hline
\end{tabular}

was utilized for the boundary layer (Nakanishi and Niino 2006) along with the 2D Smagorinsky firstorder turbulence closure model (Xue et al. 2000). There was no convective parameterization used for either domain. The model configuration is summarized in Table 1.

Analyses of the model output include the use of trajectories to determine if simulated storms are elevated or surface based. An updraft was deemed to be surface based if a majority $(>50 \%)$ of updraft trajectories originate from at or below $500 \mathrm{~m}$ above mean sea level (MSL; 200-300 m AGL). Trajectories were calculated using the Read/Interpolate/Plot (RIP) program from output saved every $2 \mathrm{~min}$. The trajectory time step is $1 \mathrm{~min}$, and data were linearly interpolated between each time step (Stoelinga et al. 2018, section 6a). Several previous mesoscale and synoptic-scale studies have utilized RIP for trajectory analyses (e.g., Schumacher and Johnson 2008; Atkins and St. Laurent 2009; Sippel et al. 2011; Rosenow et al. 2018). Our methodology for initializing forward and backward trajectories is presented in section $4 \mathrm{c}$.

\section{b. Perturbation pressure decomposition}

It has long been known (e.g., Weisman and Klemp $1982,1984)$ that supercells tend to form in environments with a large $0-6-\mathrm{km}$ bulk-wind difference (BWD). For greater clockwise curvature in a hodograph, or greater deviant storm motion to the right of a hodograph, more storm-relative helicity exists, allowing for the development of stronger cyclonic rotation within updrafts (Davies-Jones 1984; Lilly 1986), which yield areas of low pressure via the pressure diagnostic equation (e.g., Rotunno and Klemp 1982; Klemp and Rotunno 1983):

$$
\nabla^{2} p^{\prime}=-e_{i j}^{\prime 2}+\frac{1}{2}\left|\boldsymbol{\omega}^{\prime}\right|^{2}-2 \mathbf{S} \cdot \nabla_{h} w^{\prime}+\frac{\partial B}{\partial z} .
$$

In this equation, $p^{\prime}$ is the perturbation pressure, $e_{i j}^{\prime}$ is the perturbation deformation tensor, $\boldsymbol{\omega}^{\prime}$ is the vorticity vector of the perturbation flow, $\mathbf{S}$ is the environmental vertical wind shear vector, $w^{\prime}$ is the perturbation vertical velocity, and $B$ is buoyancy. To investigate the vertical accelerations that result from these pressure

temperature (shaded; ${ }^{\circ} \mathrm{F}$ ), surface winds (barbs; kt), and differential heating boundary location (solid blue line) at 1400 UTC from the inner domain. The blue dashed line encompasses a region of rain-cooled air and cloud shading from small cells southeast of the main cluster. (c) Surface dewpoint temperature (shaded; ${ }^{\circ} \mathrm{F}$ ) at 1400 UTC. The red box is the zoomed area in Fig. 11. (d) $0-1-\mathrm{km}$ storm-relative helicity $\left(\mathrm{m}^{2} \mathrm{~s}^{-2}\right)$ at 1800 UTC. (e) 0-6-km bulk wind difference ( $\mathrm{kt} ;>30 \mathrm{kt}$ shaded) at 1800 UTC. (f) 500-m mixed-layer CAPE ( $\operatorname{shaded} ; \mathrm{J} \mathrm{kg}^{-1}$ ), MLCIN $>25 \mathrm{~J} \mathrm{~kg}^{-1}$ (hatched) from the inner domain at $1800 \mathrm{UTC}$, and the locations of the ten base-state profiles used in the perturbation pressure decomposition sensitivity test (blue dots). The location of the base state used for the analysis in section $4 \mathrm{e}$ is labeled with a red dot. The 40-dBZ simulated reflectivity contour at $1 \mathrm{~km}$ (black) is overlaid on (c), (d), and (f) for reference. Panels (b)-(f) are from the inner domain. 
perturbations, it is useful to examine the vertical derivative of (1) given by

$$
\nabla^{2} \frac{\partial p^{\prime}}{\partial z}=-\frac{\partial}{\partial z} e_{i j}^{\prime 2}+\frac{1}{2} \frac{\partial}{\partial z}\left|\boldsymbol{\omega}^{\prime}\right|^{2}-2 \frac{\partial}{\partial z}\left(\mathbf{S} \cdot \nabla_{h} w^{\prime}\right)+\frac{\partial^{2} B}{\partial z^{2}} .
$$

Upward-directed accelerations arise where pressure perturbations described by (1) become more negative with height. The first two terms on the right side of (2) contribute to the vertical acceleration owing to gradients in the nonlinear dynamic perturbation pressure (APDN), the third term is the vertical acceleration owing to gradients in the linear dynamic perturbation pressure (APDL), and the last term is the vertical acceleration owing to gradients in the buoyancy perturbation pressure (APB). The sum of the APDN and APDL terms yields the total acceleration owing to gradients in the dynamic perturbation pressure (APTD).

A decomposition of perturbation pressure was completed following Rotunno and Klemp (1982) and Weisman and Rotunno (2000). To perform the perturbation pressure decomposition, we interpolated the WRF output to flat vertical levels. We used 34 vertical levels for $w$ and 33 vertical levels for $u, v$, and all scalar values, yielding a constant vertical grid spacing of $600 \mathrm{~m}$. All values of $w$ were set to zero at the bottom vertical level, $300 \mathrm{~m}$ MSL, or 10-140 m AGL. A caveat with this methodology is that relatively flat terrain is required such that the prescribed flat levels do not intersect the ground. Complex terrain may also create pressure perturbations owing to orographic effects not associated with the storm. The maximum change in terrain height over our analysis area was $130 \mathrm{~m}$.

In most previous studies utilizing perturbation pressure decomposition (e.g., Morrison 2016; Coffer and Parker 2017), a model is initialized with a horizontally homogeneous environment given by a single input sounding, which is used as the base state for the perturbation pressure decomposition. The WRF simulation analyzed herein, however, was not initialized with a horizontally homogeneous environment. We defined the base state as the horizontally averaged vertical profile over an $11 \mathrm{~km} \times 11 \mathrm{~km}$ box from the inner domain centered $90 \mathrm{~km}$ south and $30 \mathrm{~km}$ west of the maximum updraft helicity location associated with the storm of interest (e.g., red dot in Fig. 8f). These averaged basestate profiles were quality checked at each analysis time to ensure that they do not include convection, outflow, or precipitation.

To determine the sensitivity of the vertical perturbation pressure gradient accelerations to the location of the base state, tests were conducted by selecting two locations west, five locations southwest, and two locations south of a point $95 \mathrm{~km}$ southwest of the storm of interest, for a total of ten base-state profile locations (Fig. 8f). All base-state locations were upwind locations free of clouds and precipitation and sufficiently far from the storm as to not be directly influenced by it.

In this case, the base-state profiles were quite similar and produced nearly identical vertical accelerations. Two examples, chosen at random, of the accelerations produced owing to each group of terms in (2) at $1.5 \mathrm{~km}$ MSL at 1600 UTC are provided in Fig. 9 (base states located at points A and B in Fig. 8f). The APB is nearly identical between the base states (Figs. 9a,e) and the APDL is only about $0.01 \mathrm{~m} \mathrm{~s}^{-2}$ (Figs. 9b,f), about an order of magnitude less than the other components near the updraft region of the storm. The vertical perturbation pressure gradient accelerations are dominated by those owing to APDN (Figs. 9c,g), which account for nearly all of the total dynamic vertical accelerations, and are almost identical between the two base states (APTD; Figs. 9d,h). The dominance of APDN at low levels is consistent with the findings of Markowski and Richardson (2014), Skinner et al. (2015), and Coffer and Parker (2017).

The mean and standard deviation of each component of the $1.5-\mathrm{km}$ vertical perturbation pressure gradient acceleration at 1600 UTC from the entire sample of base-state locations in Fig. $8 \mathrm{f}$ are provided in Fig. 10. The means of APB, APDL, and APDN at 1600 UTC (Figs. 10a,c,e) are similar to the examples provided in Figs. 9a-c and 9e-g. The standard deviations of APB and APDN (Figs. 10b,f) are both an order of magnitude smaller than the mean accelerations, indicating small variation relative to the mean among the sample and little sensitivity to base-state location. The standard deviation of APB (Fig. 10b) is constant because changes in the base state only change the magnitude of APB, not the spatial pattern (Doswell and Markowski 2004). The APDL exhibits the largest relative standard deviation, up to $0.01 \mathrm{~m} \mathrm{~s}^{-2}$ in an area with $0.01 \mathrm{~m} \mathrm{~s}^{-2}$ vertical acceleration (Figs. 10c,d), but APDL is also approximately an order of magnitude less than the total acceleration, which is dominated by APDN (Fig. 9). The standard deviations of APDL and APDN are identical (Figs. 10d,f) because the perturbation pressure decomposition code first calculates the total dynamic perturbation pressure, then calculates the linear dynamic perturbation pressure, and treats the nonlinear dynamic perturbation pressure as a residual.

Our sensitivity tests indicate that changes in bulk shear on the order of $10 \mathrm{kt}$ or in MLCAPE on the order of $1000 \mathrm{~J} \mathrm{~kg}^{-1}$ (in an environment with around $30 \mathrm{kt}$ of bulk shear and $3000 \mathrm{~J} \mathrm{~kg}^{-1}$ MLCAPE) have little effect on the perturbation pressure decomposition. 

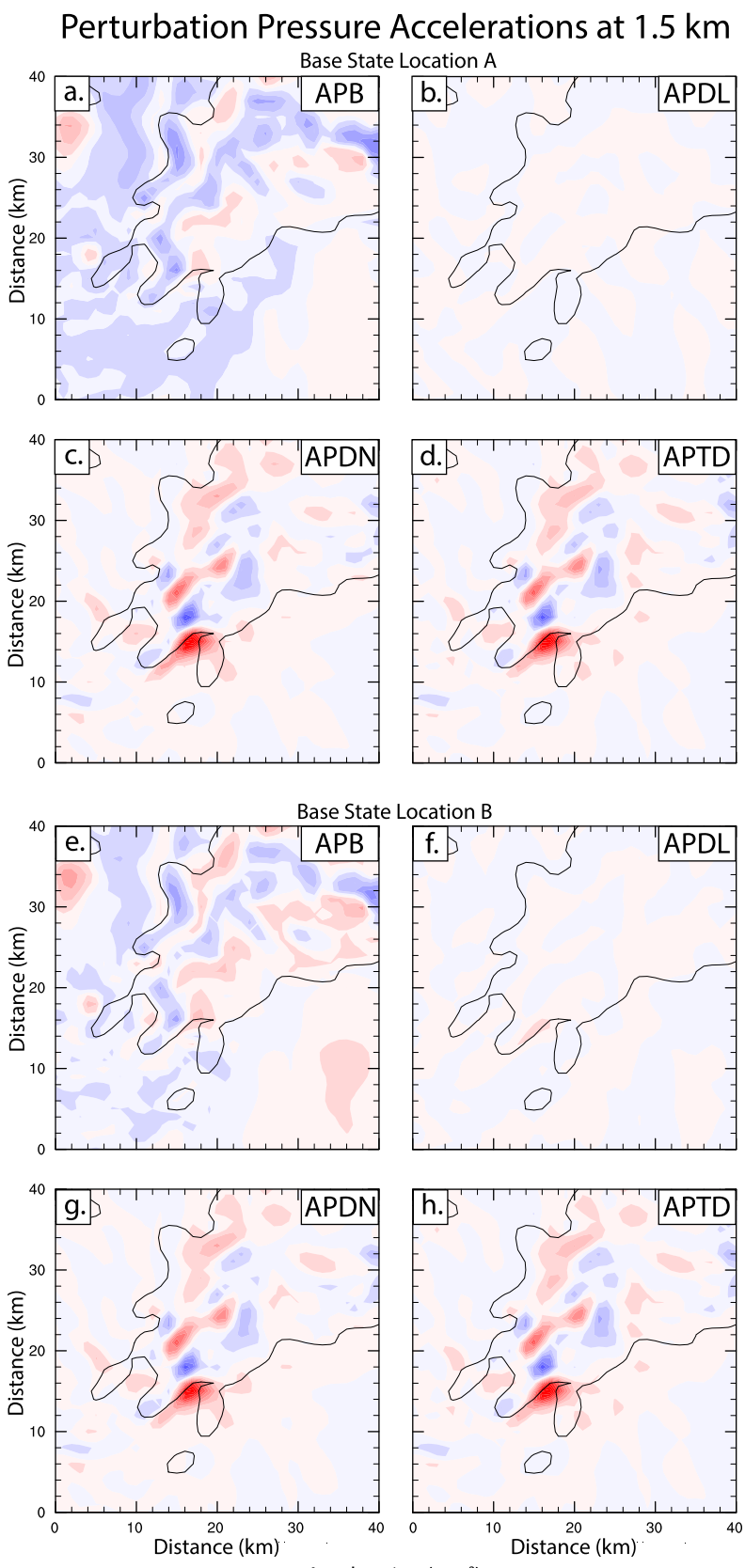

Acceleration $\left(\mathrm{m} \mathrm{s}^{-2}\right)$

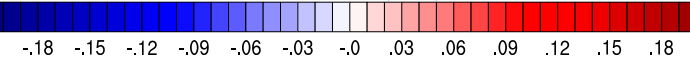

FIG. 9. Vertical accelerations $\left(\mathrm{m} \mathrm{s}^{-2}\right.$; shaded) at $1.5 \mathrm{~km}$ MSL owing to vertical gradients in the (a) buoyancy (APB), (b) linear dynamic (APDL), (c) nonlinear dynamic (APDN), and (d) total dynamic (APTD) components of the perturbation pressure. The $40-\mathrm{dB} Z$ simulated reflectivity contour at $1 \mathrm{~km}$ is in black. The perturbation pressure decomposition was performed using the base state centered at location A in Fig. 8f at 1600 UTC. (e)-(h) As in (a)-(d), but using the base state centered at location B in Fig. 8f.
Regardless, it is advised to choose a base-state location with vertical wind shear and buoyancy profiles representative of the near-storm environment because APDL and APB depend on these quantities. Having completed these sensitivity tests, we are confident that our perturbation pressure decomposition is reliable and suitable for further analysis in section 4e.

\section{WRF Model simulation}

Key features of interest that we wanted to simulate included nocturnal convection in Iowa, an MCV, elevated convective lines in Illinois, a transition from a linear to supercellular mode near the Illinois-Indiana border around the same time as observed, and the development of supercells with strong near-surface rotation near a differential heating boundary. Many simulations with different model parameters produced a bowing MCS over Indiana, which is not desirable. The simulation presented herein best met all of these criteria.

\section{a. Overview of simulation}

The WRF Model accurately simulates the mesoscale environment on 24 August 2016, capturing the MCV that moved across northern Illinois (cf. Figs. 4a and 8a). Although the 500-hPa winds associated with the simulated MCV are slightly weaker than in the RAP analysis, the location and movement of the MCV match observations fairly well. Simulated surface winds and temperatures also match observations at 1400 UTC quite well (Figs. 3a, 8b). The simulation captures the differential heating boundary over central Illinois and Indiana and the associated wind shift. The temperature of the outflow (Fig. 8b) beneath the simulated convection (Fig. 8c) at $1400 \mathrm{UTC}$ is around $70^{\circ} \mathrm{F}$, similar to observations and only about $5^{\circ} \mathrm{F}$ cooler than the ambient environment. Furthermore, the simulated surface winds within outflow are not surging outward away from the convection, consistent with the lack of surging gust fronts in radar and surface observations. The model produces slightly higher dewpoints than were observed, with widespread $74^{\circ}-75^{\circ} \mathrm{F}$ dewpoints over central and southern Illinois, while observed dewpoints ranged from $71^{\circ}$ to $75^{\circ} \mathrm{F}$ (cf. Figs. 3a and $8 \mathrm{c}$ ). The simulation produces one well-defined cluster and some scattered, leading convection (Fig. 11a) that eventually dissipates as cluster 1 does in the observations.

Several severe weather parameters at 1800 UTC, around the time that the observed storms started to become supercells, were closely simulated as well. The simulation captures an area of $0-1-\mathrm{km}$ SRH greater than $100 \mathrm{~m}^{2} \mathrm{~s}^{-2}$ in eastern Illinois and northern Indiana (cf. Figs. $4 \mathrm{~b}$ and $8 \mathrm{~d}$ ) collocated with $0-6-\mathrm{km}$ bulk shear 

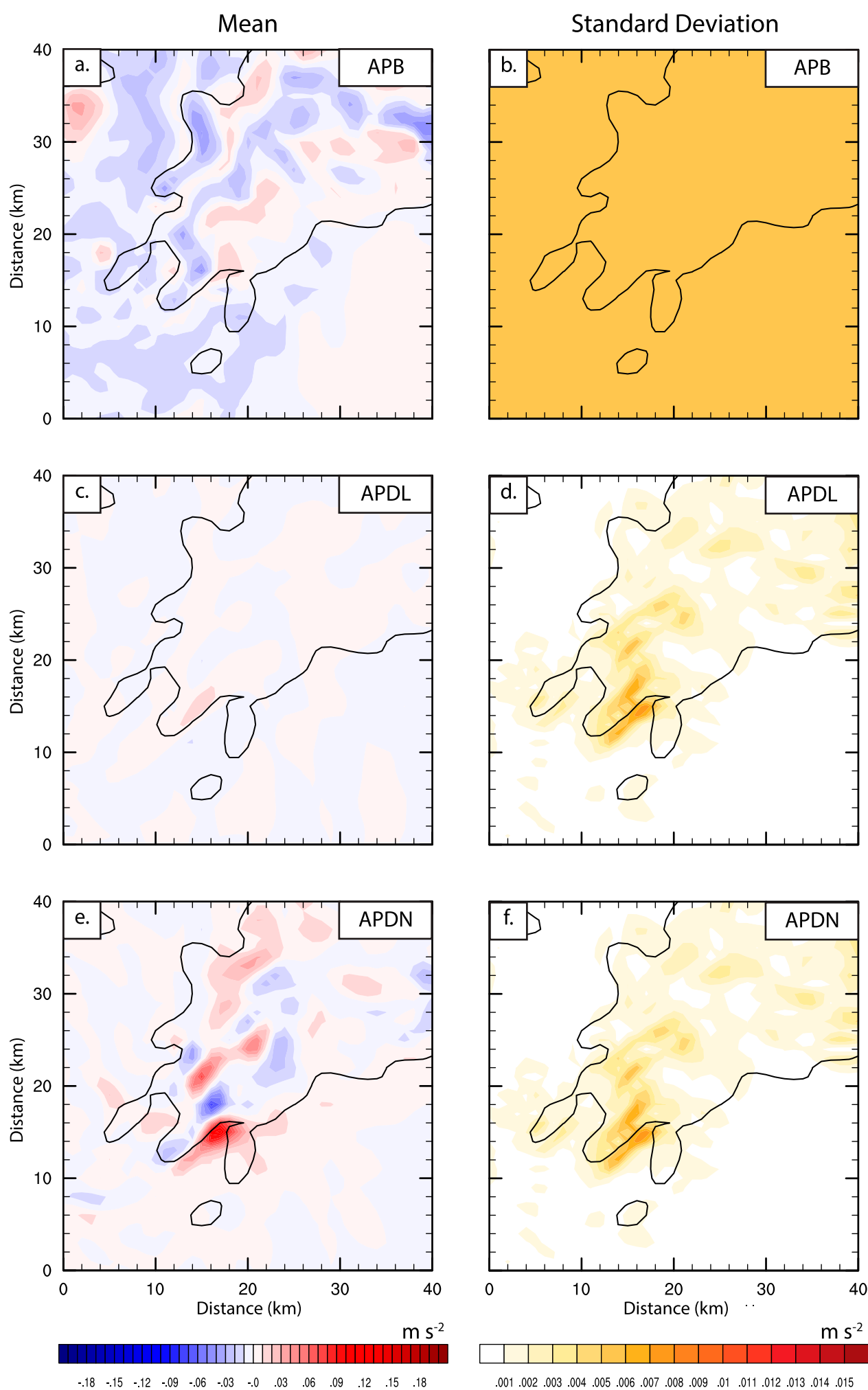

.001 .002 .003 .004 .005 .006 .007 .008 .009 .01 .011 .012 .013 .014 .015

FIG. 10. The mean (a) APB, (c) APDL, and (e) APDN ( $\mathrm{m} \mathrm{s}^{-2}$; shaded) and standard deviation of (b) APB, (d) APDL, and (f) APDN ( $\mathrm{m} \mathrm{s}^{-2}$; shaded) at $1.5 \mathrm{~km}$ produced from the sample of ten base-state locations in Fig. 8f at 1600 UTC. The 40-dBZ simulated reflectivity contour at $1 \mathrm{~km}$ is in black. 
Simulated Reflectivity, Surface Temperature, Total Column Integrated Ice, and Surface Winds
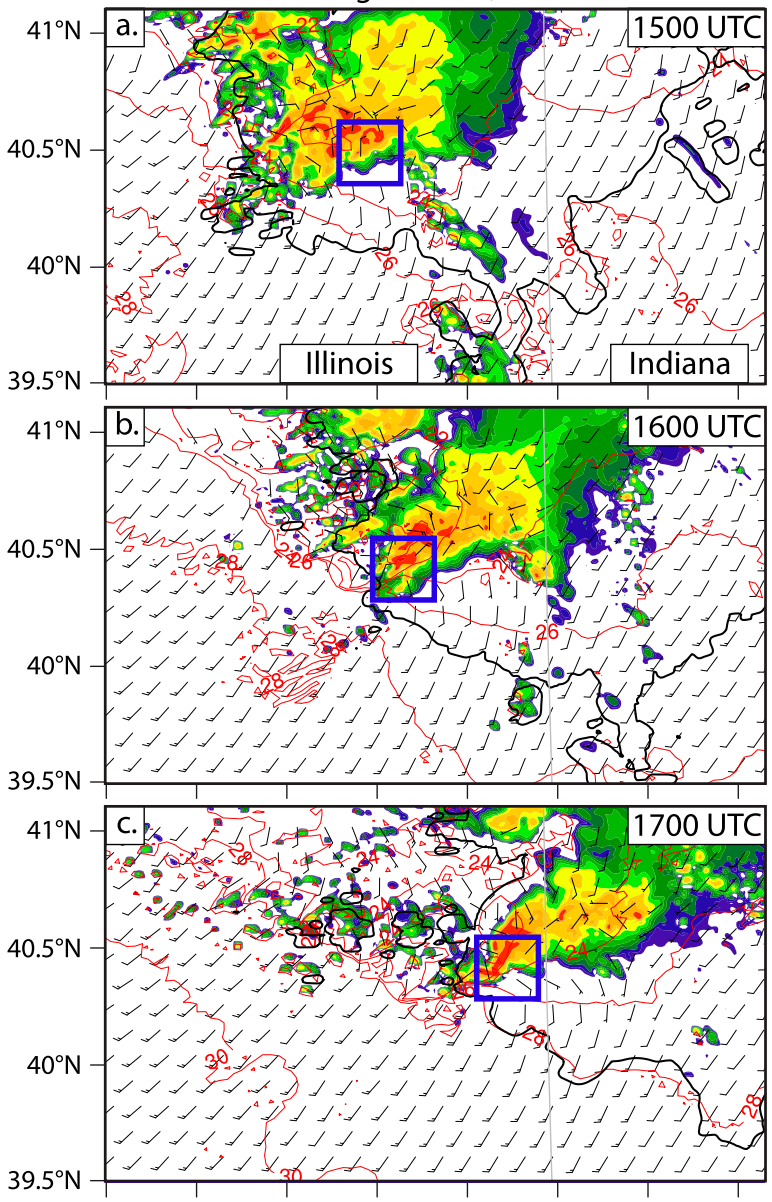

$90^{\circ} \mathrm{W} \quad 89.5^{\circ} \mathrm{W} \quad 89^{\circ} \mathrm{W} \quad 88.5^{\circ} \mathrm{W} \quad 88^{\circ} \mathrm{W} \quad 87.5^{\circ} \mathrm{W} \quad 87^{\circ} \mathrm{W} \quad 86.5^{\circ} \mathrm{W}$

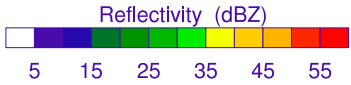

FIG. 11. Simulated 1-km reflectivity (dBZ; shaded), surface temperature $\left({ }^{\circ} \mathrm{C}\right.$; red contours), total column integrated ice of $0.1 \mathrm{~kg} \mathrm{~m}^{-2}$ (black contour), and surface winds (barbs; $\mathrm{kt}$ ) at (a) 1500, (b) 1600, and (c) 1700 UTC. The light gray line is the Illinois-Indiana state line for reference. The blue boxes are the zoomed areas at the corresponding times in Fig. 12. The domain is indicated in Fig. 8c.

greater than $30 \mathrm{kt}$ (cf. the region southeast of the MCV in Figs. 4a and 8e). The simulated area of MLCAPE greater than $2000 \mathrm{~J} \mathrm{~kg}^{-1}$ is similar to that in the 1800 UTC RAP analysis (cf. Figs. 4c and 8f), although the differential heating boundary is sharper in the simulation, likely owing to finer grid spacing.

In the simulation, a multicellular storm cluster is located over east-central Illinois at 1500 UTC. Several individual updrafts at $4 \mathrm{~km}$ are identifiable and a small area of relative vertical vorticity on the order of $0.01 \mathrm{~s}^{-1}$ at $1 \mathrm{~km}$ is present on the right flank of a larger updraft in the cluster (vortex 1; Figs. 11a and 12a). The $0.1 \mathrm{~kg} \mathrm{~m}^{-2}$ contour of total column integrated ice is used as a proxy for the extent of the anvil cloud, which extends eastsoutheastward from the storms. A surface wind shift exists along the differential heating boundary, separating southwesterly winds south of the boundary from slower southerlies to its north, as was observed (Fig. 11). A time series of maximum relative vertical vorticity $\zeta$ at $1 \mathrm{~km}$ and mean vertical velocity $w$ at $4 \mathrm{~km}$ for the southernmost storm in the cluster (Fig. 13) reveals several weak updraft pulses before 1600 UTC, a peak in maximum $1-\mathrm{km} \zeta$ at 1512 UTC associated with vortex 1 , and the development of a new 1-km vortex around 1530 UTC (vortex 2).

Between 1600 and 1700 UTC, a dominant updraft steadily intensifies, with a corresponding increase in maximum $1-\mathrm{km} \zeta$ associated with vortex 2 from 0.015 to $0.03 \mathrm{~s}^{-1}$ (Fig. 13). At 1700 UTC, vortex 2 is $4.5 \mathrm{~km}$ deep (not shown), in the notch of a hook echo, and collocated with a single intense updraft, characteristic of a mesocyclone (Fig. 12c). The storm also exhibits deviant rightward (toward the southeast) motion by this time. The differential heating boundary strengthens southeast of the cluster as solar heating increases temperatures outside of the anvil cover by 1700 UTC (cf. the relative locations of the $24^{\circ}$ and $28^{\circ} \mathrm{C}$ isotherms in Figs. $11 \mathrm{~b}, \mathrm{c}$ ). By 1730 UTC, vortex 2 weakens substantially as a downdraft develops owing to mesocyclone cycling as the old updraft and vortex 2 move north atop outflow (near $x=24 \mathrm{~km}$ and $y=22 \mathrm{~km}$ in Fig. 12d) while a new updraft develops to the south (near $x=14 \mathrm{~km}$ and $y=$ $10 \mathrm{~km}$ in Fig. 12d). The new updraft grows in size and strength in the simulated reflectivity notch through 1800 UTC (Fig. 12e), and 1-km $\zeta$ increases above $0.02 \mathrm{~s}^{-1}$ by 1830 UTC (Fig. 13). At 1900 UTC, a mesocyclone with concentrated $\zeta$ at $1 \mathrm{~km}$ up to $0.04 \mathrm{~s}^{-1}$, a single strong updraft at $4 \mathrm{~km}$, and a hook echo are present (Fig. 12f).

In summary, the southernmost storm transitions from unorganized (and elevated, as presented in sections $4 \mathrm{~b}$ and $4 c$ ) convection to a surface-based supercell between 1500 and 1700 UTC in the simulation, as was observed from 1600 to 1830 UTC with the Crawfordsville supercell. Although the first simulated supercell develops earlier and thus farther west than was observed, we believe that this simulation depicts the events of 24 August 2016 well.

While numerous simulations of supercells within favorable kinematic and thermodynamic environments have been analyzed in the past (e.g., Klemp and Wilhelmson 1978; Weisman and Klemp 1982, 1984; Nowotarski et al. 2015; Coffer and Parker 2015, 2017; Warren et al. 2017), the development of a supercell from initially disorganized elevated convection remains relatively unexplored. Thus, the remainder of the analysis focuses on the transition from 
4 km Vertical Velocity, 1 km Vertical Vorticity, Reflectivity, and Surface Winds

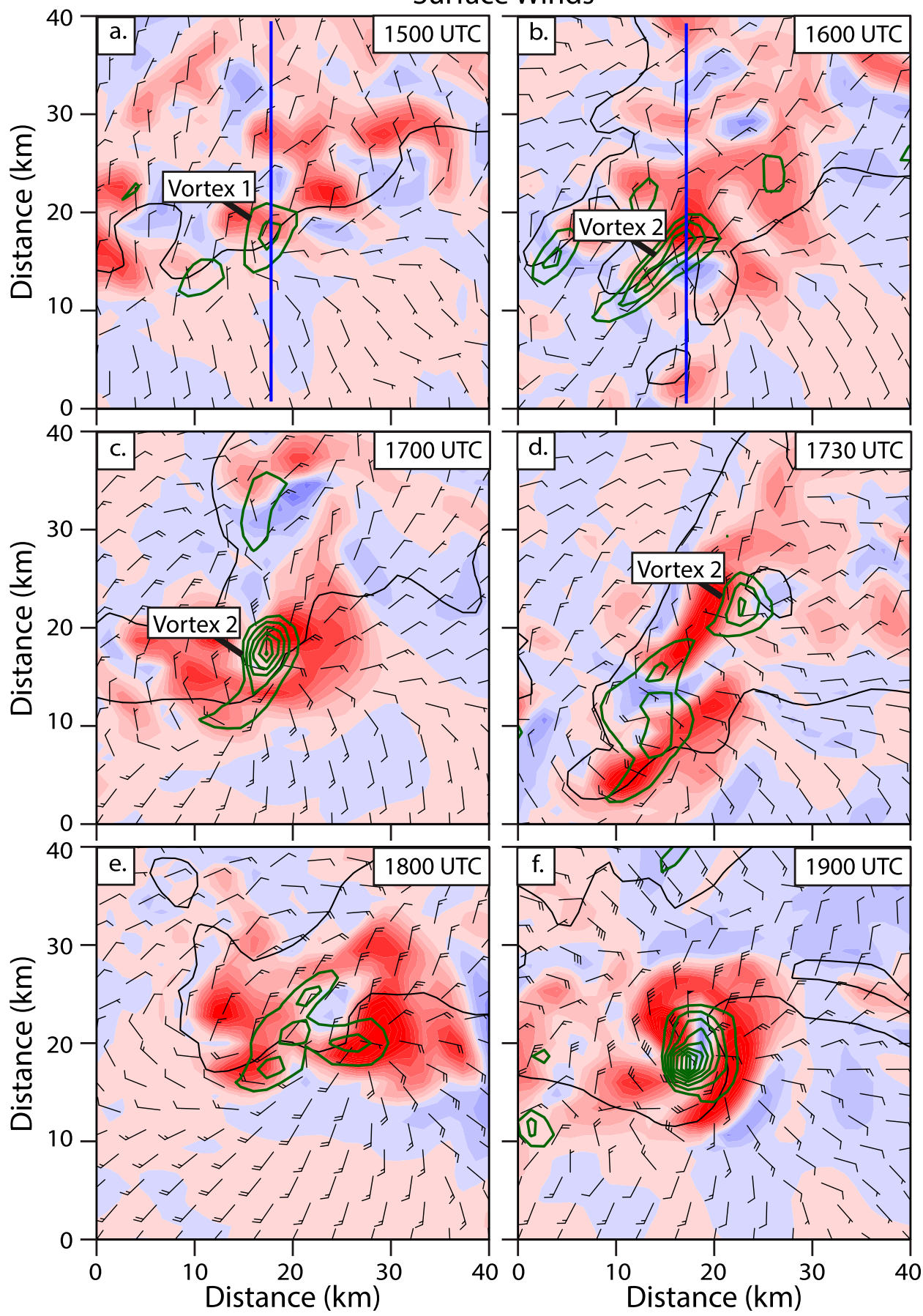

$\mathrm{ms}^{-1}$

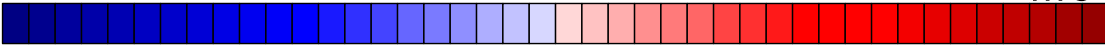

$\begin{array}{lllllllllllllllllllll}-40 & -36 & -32 & -28 & -24 & -20 & -16 & -12 & -8 & -4 & 0 & 4 & 8 & 12 & 16 & 20 & 24 & 28 & 32 & 36 & 40\end{array}$

FIG. 12. Vertical velocity at $4 \mathrm{~km}\left(\mathrm{~m} \mathrm{~s}^{-1}\right.$; shaded), relative vertical vorticity at $1 \mathrm{~km}$ contoured every $0.005 \mathrm{~s}^{-1}$ beginning at $0.005 \mathrm{~s}^{-1}$ (green), surface winds (kt; barbs), and the $40-\mathrm{dB} Z$ simulated reflectivity contour at $1 \mathrm{~km}$ (black) at (a) 1500, (b) 1600, (c) 1700, (d) 1730, (e) 1800, and (f) 1900 UTC. Vortex 1 is labeled in (a) and vortex 2 is labeled in (b)-(d). The dark blue lines in (a) and (b) are the locations of the vertical cross sections at the corresponding times in Fig. 14. The numbers on the $x$ and $y$ axes are provided as a scale of distance; the location differs from panel to panel and follows the maximum vertical vorticity at $1 \mathrm{~km}$. The domain of this figure is indicated in Fig. 11. 


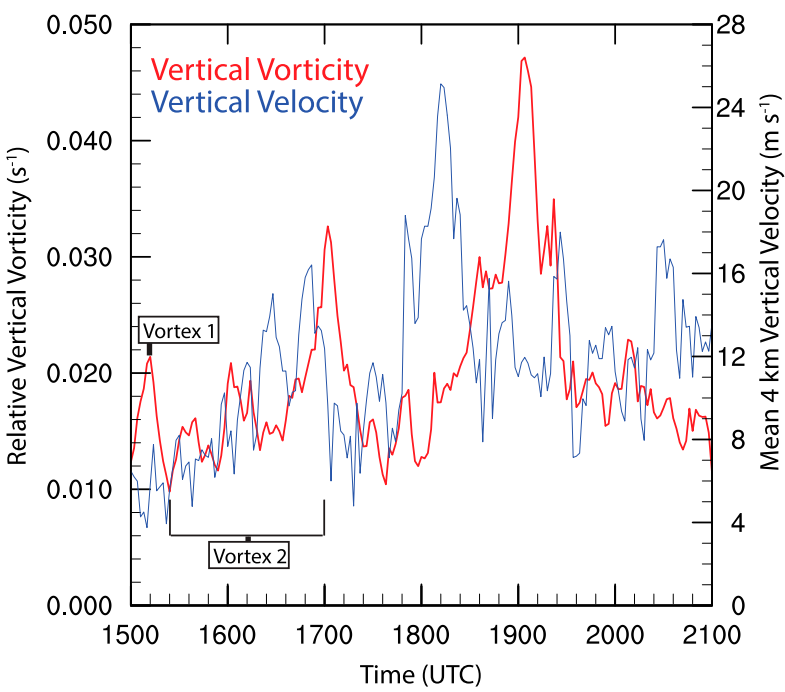

FIG. 13. Time series of maximum $1-\mathrm{km} \zeta$ (red) and mean $4-\mathrm{km} w$ (blue) calculated over a $5 \mathrm{~km} \times 5 \mathrm{~km}$ box centered on the maximum $4-\mathrm{km} w$. The portions of the $1-\mathrm{km} \zeta$ time series associated with vortex 1 and vortex 2 are annotated.

disorganized elevated convection to an intense surfacebased supercell.

\section{b. Vertical cross sections}

Vertical cross sections are utilized to further investigate the structure of the developing storm in the simulation. The vertical cross sections presented are taken from south to north over a distance of $40 \mathrm{~km}$ through the area of greatest vorticity at $1 \mathrm{~km}$. The strongest updraft associated with the $1-\mathrm{km}$ vorticity maximum is within $2 \mathrm{~km}$ of the cross-section plane. At 1500 UTC, there are multiple elevated updrafts rooted above $2 \mathrm{~km} \mathrm{MSL} \mathrm{(Fig.} \mathrm{14a).} \mathrm{Vertical}$ vorticity of both signs, less than $0.01 \mathrm{~s}^{-1}$, straddles the updrafts above $2 \mathrm{~km}$, owing to tilting of weak environmental horizontal vorticity (not shown). Vortex 1 remains confined below $2 \mathrm{~km}$ and only lasts for $25 \mathrm{~min}$ before it moves northeastward into outflow and dissipates (not shown). We demonstrate in section $4 \mathrm{c}$ that vortex 1 is a result of a small amount of air from below $1 \mathrm{~km}$ entering the updraft. Most vertical wind shear, and thus horizontal vorticity, is confined below $1 \mathrm{~km}$ and especially within the lowest few $100 \mathrm{~m}$ (cf. areas south of $y=17 \mathrm{~km}$ in Fig. 15a with Fig. 2; areas north of $y=17 \mathrm{~km}$ in Fig. 15a are within outflow and are thus not representative of the ambient environment). By 1530 UTC, vortex 2 has developed and exhibits vertical vorticity on the order of $0.01 \mathrm{~s}^{-1}$ below $1 \mathrm{~km}$ (Fig. 14b). Although weak vertical vorticity develops in the elevated updrafts, it is expected that much stronger low-level vertical vorticity could result as updrafts ingest more air from the lowest few $100 \mathrm{~m}$ and tilt the horizontal vorticity generated by the strong vertical wind shear in this layer $\left(>0.28 \mathrm{~s}^{-1}\right.$;
Fig. 15a). Indeed, Fig. 15b confirms that only weak tilting and little to no stretching is occurring at $0.5 \mathrm{~km}$ at 1530 UTC and a trajectory analysis (section 4c) confirms that storms were still elevated at this time.

Additional updrafts that are stronger near and below $2 \mathrm{~km}$ MSL develop through 1550 UTC (Fig. 14c). A vortex couplet still straddles the northernmost updraft, whereas cyclonic vertical vorticity is collocated with the next two updrafts to the south (Fig. 14c). Then 10 minutes later, at $1600 \mathrm{UTC}$, there is an 8-km-deep surface-based (proved in section $4 \mathrm{c}$ ) updraft collocated with vortex 2 $\left(\zeta>0.015 \mathrm{~s}^{-1}\right)$, extending from near the surface to over $2 \mathrm{~km}$ MSL (Fig. 14d). Both tilting and stretching are active near this updraft and along the rear-flank gust front at 1600 UTC (Fig. 15c).

By 1620 UTC, multiple updrafts are still present, but the updrafts are larger, deeper, and stronger, with maximum updraft speeds greater than $20 \mathrm{~m} \mathrm{~s}^{-1}$ (Fig. 14e). These updrafts merge into one deep, rotating updraft atop vortex 2 at 1630 UTC (Fig. 14f), extending to roughly $16 \mathrm{~km}$ MSL and exhibiting vertical vorticity greater than $0.015 \mathrm{~s}^{-1}$ from 1 to $6 \mathrm{~km}$ MSL.

The transition from unorganized, elevated convection to a surface-based supercell is not instantaneous in this case, but rather requires roughly $60 \mathrm{~min}$ and multiple updraft pulses before one deep rotating updraft develops. In the next section, we utilize trajectory analyses to confirm that the storms began ingesting near-surface air prior to the development of supercellular characteristics.

\section{c. Trajectory analysis}

Backward trajectories are utilized to determine at what level parcels within the updrafts originated. A $3 \times$ 3 grid of 9 trajectories, each separated by $1 \mathrm{~km}$, was centered on the location and height of the maximum vertical velocity and the trajectories were integrated backward in time to 1400 UTC, when the inner domain was initialized. A robustness check was conducted by initializing a $5 \mathrm{~km} \times 5 \mathrm{~km} \times 4 \mathrm{~km}$ box of backward trajectories also centered on the strongest updraft; the $3 \times$ 3 grid of trajectories shown herein is representative of this larger set. At 1530 UTC, the parcels within the midlevel updraft all originate above $1 \mathrm{~km}$ MSL (Figs. 14b and 16a) and enter the updraft from the west-southwest (Fig. 17a), consistent with the winds at this altitude (Fig. 18a). A model sounding from the starred location in Fig. 17a at 1510 UTC, while the parcels are at this location and $20 \mathrm{~min}$ before they are within the maximum updraft, indicates that the level of free convection (LFC) for an undilute surface parcel is below $1 \mathrm{~km}$, but that such a parcel does not become significantly buoyant until it ascends above $850 \mathrm{hPa}$, or about $1.5 \mathrm{~km}$ AGL, owing to the nearly moist adiabatic environmental lapse rate between 

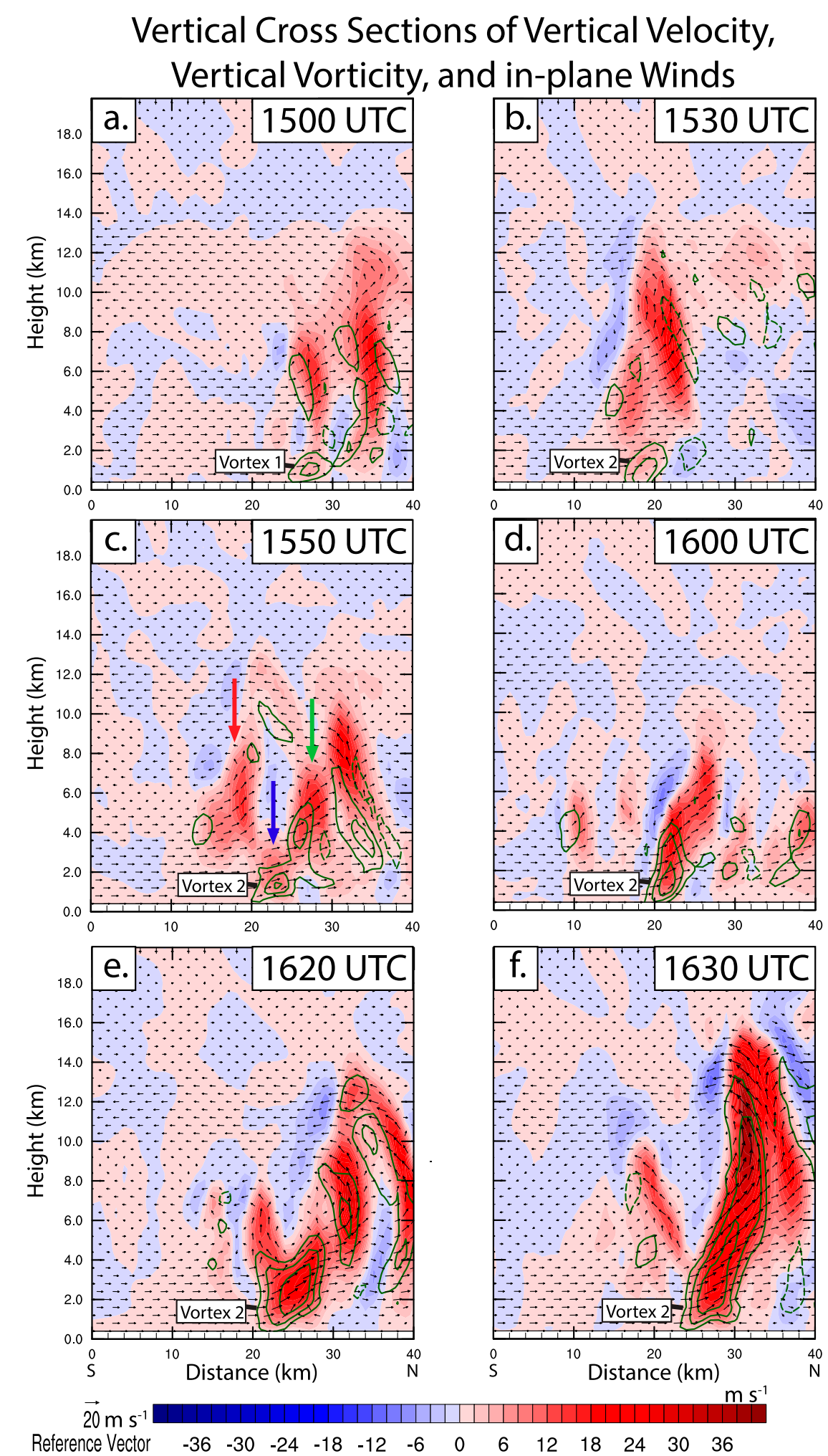

$\begin{array}{llllllllllllll}\text { Reference Vector } & -36 & -30 & -24 & -18 & -12 & -6 & 0 & 6 & 12 & 18 & 24 & 30 & 36\end{array}$

FIG. 14. South-north vertical cross sections of vertical velocity $\left(\mathrm{m} \mathrm{s}^{-1}\right.$; shaded), vertical vorticity ( $\mathrm{s}^{-1}$; green; positive values solid and negative values dashed) contoured every $0.005 \mathrm{~s}^{-1}$ (zero contour omitted for clarity), and plane-parallel wind vectors $\left(\mathrm{m} \mathrm{s}^{-1}\right.$; arrows) at (a) 1500, (b) 1530, (c) 1550, (d) 1600, (e) 1620, and (f) 1630 UTC. Vortex 1 is 
925 and $850 \mathrm{hPa}$ (Fig. 18a). Parcels originating around $850 \mathrm{hPa}$, however, do not encounter such a neutrally buoyant layer, which is why the trajectories originate around 1.5 MSL and the storms are still elevated at this time (Fig. 16a). Since most of the vertical wind shear is below $1 \mathrm{~km}$ (Figs. 2, 15a, and 18a), these elevated updrafts do not acquire significant rotation via tilting of environmental horizontal vorticity (Figs. 14a,b and 15b).

Back trajectories at 1546 UTC (Fig. 16b) indicate that the majority of parcels within the updrafts at this time still originate above $1 \mathrm{~km}$. By 1550 UTC (Fig. 16c), some parcels from below $1 \mathrm{~km}$ are feeding into the updraft (green arrow in Fig. 14c); the parcels from below $1 \mathrm{~km}$ enter the updraft from the southwest, while parcels from above $1 \mathrm{~km}$ flow from the west-southwest, owing to the veering winds with height (Fig. 17b). A model sounding at 1530 UTC from the starred location in Fig. 17b indicates that near-surface parcels experience more positive buoyancy just above their LFC than 20 min earlier (cf. Figs. 18a,b) owing to additional solar heating, supportive of near-surface air beginning to enter the updrafts. By 1558 UTC (Fig. 16d), almost all of the trajectories originate below $1 \mathrm{~km}$, some from the lowest few $100 \mathrm{~m}$, and the convection is continually surface based after this time, as discussed below.

We corroborated these findings using a plethora of forward trajectories to determine when our criterion of at least $50 \%$ of updraft trajectories originating at or below $500 \mathrm{~m}$ MSL for surface-based convection was met. We initiated a $500 \mathrm{~km} \times 200 \mathrm{~km} \times 2.5 \mathrm{~km}$ box of forward trajectories with horizontal spacing of $1 \mathrm{~km}$, and vertical spacing of $500 \mathrm{~m}$, and a lowest level of $0.5 \mathrm{~km}$ MSL (a total of 6000 trajectories) south of vortex 1 every 2 min from 1500 to 1520 UTC to investigate those that enter the updrafts associated with this vortex (Fig. 14a). We found that while some air from $500 \mathrm{~m}$ enters the updrafts, the number of trajectories originating at $500 \mathrm{~m}$ is fairly small ( $25 \%$ of only $30-50$ trajectories; Fig. 19a). We also initiated trajectories south of vortex 2 from 1526 to 1630 UTC to investigate the updrafts associated with this vortex (Fig. 14b). These updrafts are mostly ingesting air from 1.5 to $2.5 \mathrm{~km}$ between 1526 and 1552 UTC, but some air from $1 \mathrm{~km}$ also enters the updrafts during this time (Fig. 19b). After 1552 UTC, a dominant updraft develops and generally ingests air from $500 \mathrm{~m}$ (up to $90 \%$ of 60-180 trajectories; Fig. 19b). Vortex 1 appears to be the result of an attempt at surface-based convection initiation and is only associated with weak, small updrafts. Multiple elevated updrafts pass over vortex 2, however, before a single stronger updraft that ingests air from below $1 \mathrm{~km}$ develops atop this circulation. We investigate these updrafts further in section $4 \mathrm{e}$ using a pressure perturbation decomposition.

This analysis indicates that the elevated updrafts begin to ingest a significant amount of air from below $1 \mathrm{~km}$ after 1552 UTC, yielding the generation of substantial vertical vorticity within vortex 2 below $1 \mathrm{~km}$ via tilting and subsequent stretching. The updrafts that move atop vortex 2 become increasingly collocated with strong cyclonic vertical vorticity and continue to intensify through 1630 UTC, by which time one deep rotating updraft exists. This analysis is also consistent with that presented in section $4 \mathrm{~b}$, which depicts vortex 2 developing into a strong mesocyclone between 1550 and 1600 UTC (Figs. 14c,d), when the updraft becomes surface based. Parcels entering this updraft originate from a broad area with $0-1-\mathrm{km}$ SRH between 150 and $350 \mathrm{~m}^{2} \mathrm{~s}^{-2}$ and pass through an area of enhanced $0-1-\mathrm{km} \mathrm{SRH}>400 \mathrm{~m}^{2} \mathrm{~s}^{-2}$ beneath the anvil southeast of the storm (Figs. 20a,b), which likely contributes to the rapid intensification of vortex 2 in the dominant updraft once it becomes surface based. We investigate the origins of this area of enhanced SRH in the following section.

\section{d. Horizontal vorticity budget}

In the previous section, we demonstrated that updrafts begin ingesting near-surface air just before 1600 UTC. In this section, we calculate vorticity budgets along backward trajectories initiated within the strongest updraft at $1 \mathrm{~km}$ MSL at 1600 UTC (Fig. 14d), permitting an investigation of the processes by which these parcels acquire horizontal vorticity and the cause of the large $\left(>400 \mathrm{~m}^{2} \mathrm{~s}^{-2}\right.$ ) 0-1-km SRH southeast of the storm under the anvil (Figs. 20a,b). We used 1600 UTC as the initiation time of these trajectories because rotation is strong and consistent by this time.

In the region of SRH $>400 \mathrm{~m}^{2} \mathrm{~s}^{-2}$, there is larger horizontal vorticity, stronger storm-relative winds, and the two vectors are more parallel than outside of the anvil cover, all of which yield larger SRH (Fig. 20c).

labeled in (a) and vortex 2 is labeled in (b)-(f). The green arrow in (c) indicates the updraft used for the trajectory analysis in Figs. 16b and 16c, the blue arrow indicates the updraft that dissipates in Figs. 24a and 24b, and the red arrow indicates a portion of the updraft that persists in Fig. 24c. The numbers along the $x$-axes indicate the southnorth distance along each cross section. 

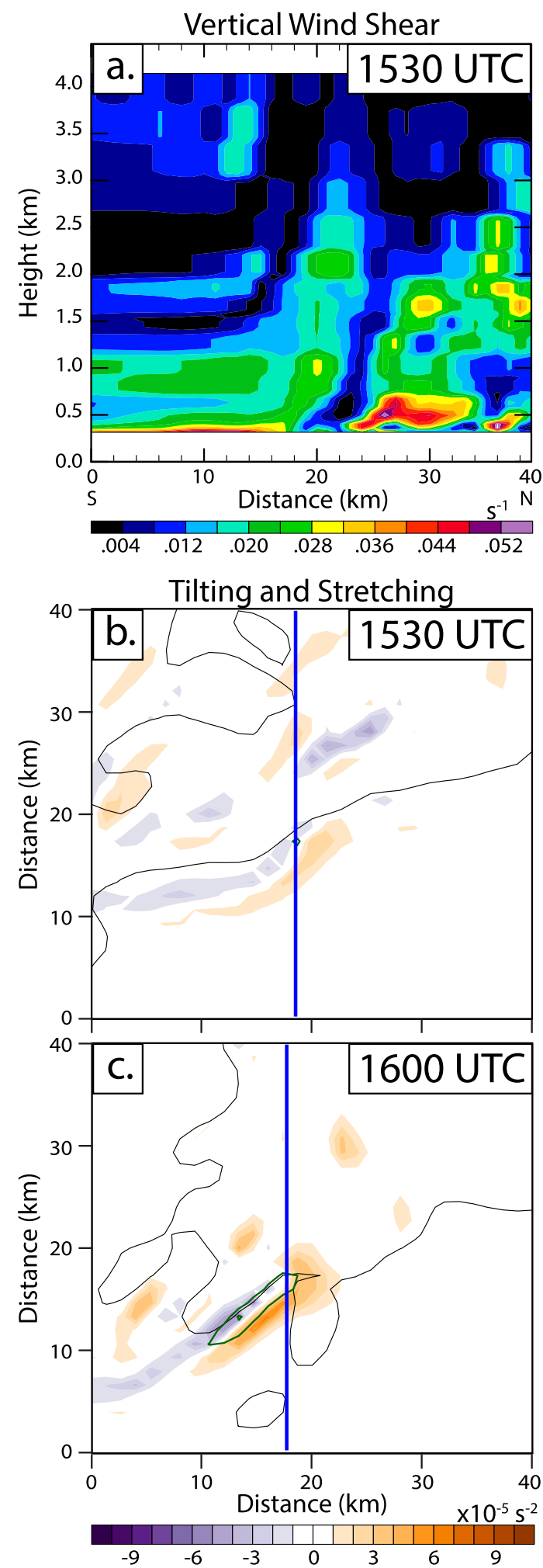

FIG. 15. (a) Vertical wind shear $\left(\mathrm{s}^{-1}\right)$ in the surface to $4-\mathrm{km}$ layer in the plane of the vertical cross section in Fig. 14b at 1530 UTC. The numbers along the $x$ axis indicate the south-north distance along the cross section. Tilting of horizontal vorticity at $0.5 \mathrm{~km}$
The storm-relative winds are stronger under the anvil because the ground-relative winds are more southerly there, as opposed to southwesterly (Fig. 11b), owing to less mixing down of westerly momentum (e.g., Fig. 18). Weaker mixing is manifested by the lower values of turbulent kinetic energy (TKE; Fig. 20c) under the anvil where there is less solar heating (Frame and Markowski 2010). A model sounding from underneath the anvil at 1540 UTC (Fig. 18c; location indicated in Fig. 20a) exhibits backed winds at the surface and increased stability below $500 \mathrm{~m}$ when compared to Figs. 18a,b, as expected. With horizontal vorticity vectors oriented toward the northwest, the stronger storm-relative winds become increasingly parallel to the horizontal vorticity vectors under the anvil, increasing the SRH. Between 1410 and 1600 UTC, storm motion and SRH remain relatively constant $\left(>400 \mathrm{~m}^{2} \mathrm{~s}^{-2}\right)$ underneath the anvil, while it decreases to around $200 \mathrm{~m}^{2} \mathrm{~s}^{-2}$ outside of the anvil (Figs. 20a,b). Furthermore, storminduced inflow acceleration, owing to surface low pressure near the storm (not shown), aids to back winds east of the storm (Brooks et al. 1994; Parker 2014), but the larger area of backed winds and high SRH is due to anvil shading, as that area is outside the influence of the storminduced perturbation pressure field, and is demonstrated by the vorticity budgets below.

The budgets for the $x$ and $y$ components of vorticity are given by

$$
\begin{aligned}
& \xi(t)=\xi_{0}+\int_{t_{0}}^{t}\left(\eta \frac{\partial u}{\partial y}+\zeta \frac{\partial u}{\partial z}+\xi \frac{\partial u}{\partial x}+\frac{\partial B}{\partial y}\right) d t \\
& \eta(t)=\eta_{0}+\int_{t_{0}}^{t}\left(\xi \frac{\partial v}{\partial x}+\zeta \frac{\partial v}{\partial z}+\eta \frac{\partial v}{\partial y}-\frac{\partial B}{\partial x}\right) d t
\end{aligned}
$$

where $\xi$ is the $x$ component of vorticity and $\eta$ is the $y$ component of vorticity. The first two terms inside the integral in each equation are the tilting terms, the third is the stretching term, and the last is the baroclinic generation term (e.g., Marquis et al. 2016). Figure 21 displays representative inflow trajectories from a $5 \mathrm{~km} \times$ $5 \mathrm{~km}$ grid centered on the $1-\mathrm{km}$ updraft at $1600 \mathrm{UTC}$, all of which originate from below $1 \mathrm{~km}$, and Fig. 22 shows

\footnotetext{
$\left(\times 10^{-5} \mathrm{~s}^{-2}\right.$; shaded $)$, stretching of vertical vorticity at $0.5 \mathrm{~km}$ contoured every $1 \times 10^{-4} \mathrm{~s}^{-2}$ (green), and the $40-\mathrm{dBZ}$ reflectivity contour at $1 \mathrm{~km}$ (black) at (b) 1530 and (c) 1600 UTC. The blue line is the location of the vertical cross section at corresponding times in Fig. 14. The numbers on the $x$ and $y$ axes are provided as a scale of distance; the location differs from panel to panel and follows the maximum vertical vorticity at $1 \mathrm{~km}$.
} 


\section{Back Trajectories}
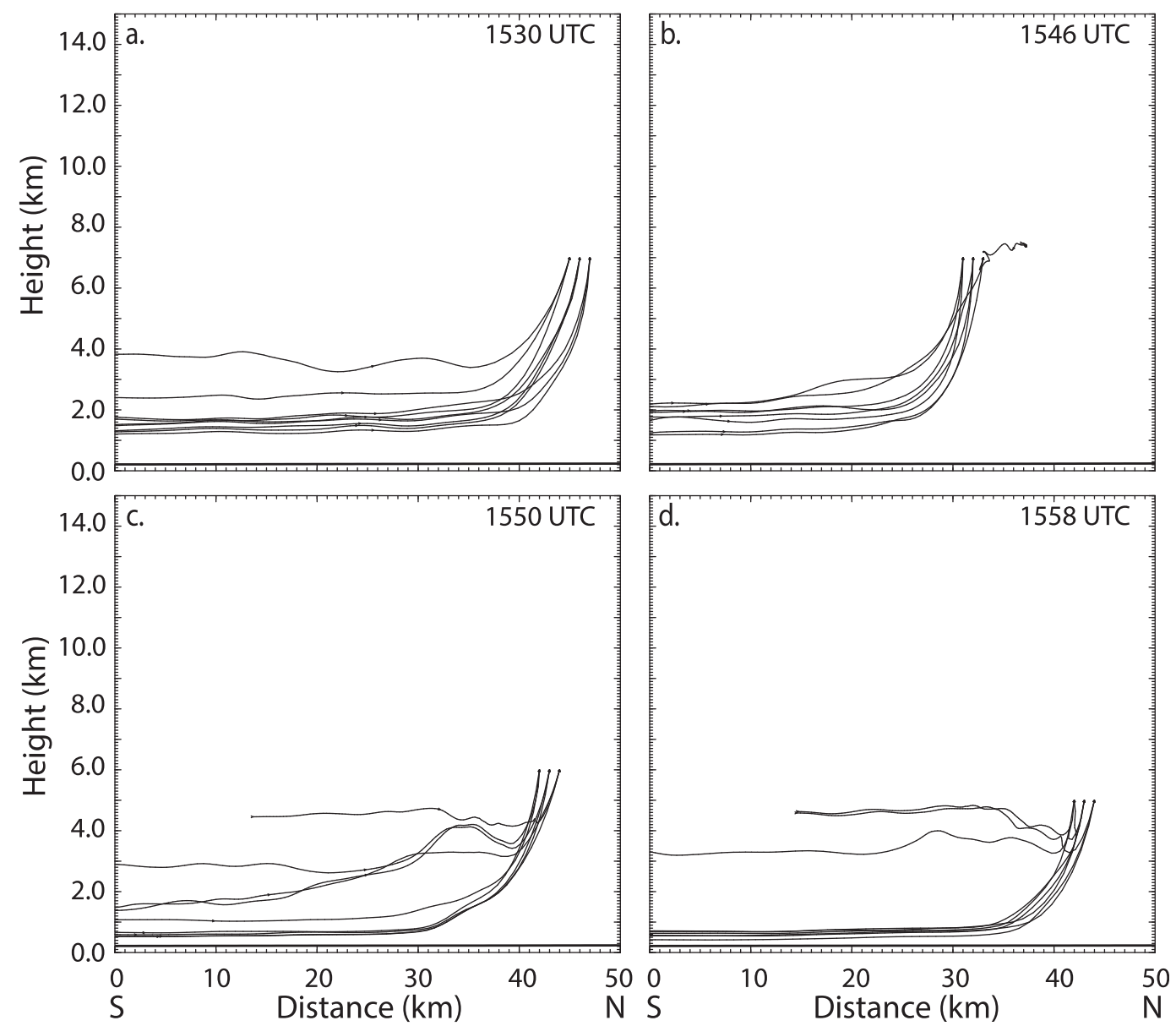

FIG. 16. South-north vertical projections of the nine backward trajectories centered on the maximum updraft at (a) 1530, (b) 1546, (c) 1550, and (d) 1558 UTC. The numbers along the $x$-axes indicate the south-north distance along each cross section.

the accumulated horizontal vorticity from each term in the vorticity equation for each trajectory. The trajectories that originate below $400 \mathrm{~m}$ exhibit the most fluctuation in and the largest values of horizontal vorticity (Figs. 21 and 22a-d), whereas the trajectories that originate just below $1 \mathrm{~km}$ exhibit relatively constant and smaller values of horizontal vorticity (Figs. 21 and $22 \mathrm{e}, \mathrm{f})$. The calculated vorticity from (3) and (4) was subtracted from the model output vorticity at each point along each trajectory to obtain a residual, which is assumed to represent frictional and subgrid-scale turbulent processes. For the near-surface (defined as within the strongly sheared layer below $400 \mathrm{~m}$ MSL in Fig. 15a) trajectories, the residual is of the same magnitude or greater than the other three terms (Figs. 22a-d), suggesting that friction and/or mixing are the dominant processes in the horizontal vorticity budget near the surface in this case. The trajectories above the strongly sheared layer do not exhibit large values for any of the terms (Figs. 22e,f). Baroclinic generation of horizontal vorticity along the edge of the anvil is relatively small (integrated magnitude $<0.017 \mathrm{~s}^{-1}$ before approaching the gust fronts), as in Frame and Markowski (2013).

Generally, horizontal vorticity is oriented toward the northwest in the inflow region (i.e., $\xi$ is negative and $\eta$ is positive; Fig. 20c). Thus, when the $x$ residual becomes more positive with time or the $y$ residual becomes more negative with time, the processes represented by the residual decrease the horizontal vorticity (Figs. 22a,b,d). Frictional generation of horizontal vorticity is to the left of parcel motion, toward the west-northwest in this case, and adds to the ambient horizontal vorticity, suggesting that frictional processes are not the dominant component of the residual. Vertical mixing, however, destroys vertical wind shear and thus decreases horizontal vorticity, which is consistent with the trends in the residual 


\section{Reflectivity, Trajectories, and Model Sounding Locations}
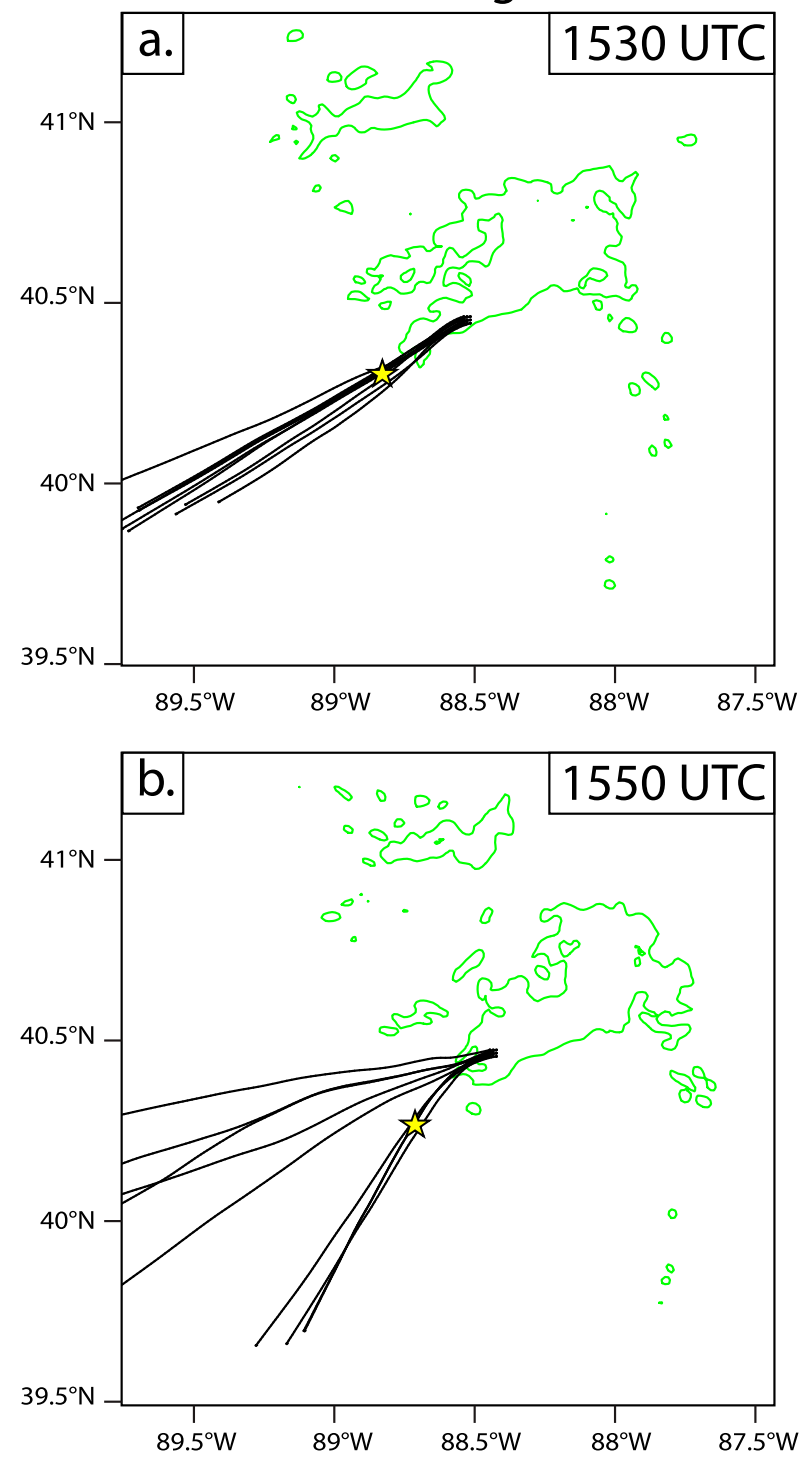

FIG. 17. Simulated reflectivity at $1 \mathrm{~km}(40 \mathrm{dBZ}$; green contour) and horizontal projections of the nine back trajectories centered on the maximum vertical velocity at (a) 1530 and (b) 1550 UTC. The star in (a) is the location of the model sounding taken at 1510 UTC in Fig. 18a, and the star in (b) is the location of the model sounding taken at 1530 UTC in Fig. 18b.

in Figs. 22a,b, d and is discussed further below. The nearsurface trajectories exhibit the largest residual values because the effects of vertical mixing are strongest within the strongly sheared near-surface layer.

Recent work investigating the accuracy of trajectories near the surface has been completed by Guchte and Dahl (2018). They explain that in simulations with freeslip lower boundaries, trajectories that dip below the lowest scalar model level may be inaccurate owing to the unrealistic constant winds with height prescribed there. Our model simulation uses the revised MM5 MoninObukhov surface layer scheme and includes a viscous sublayer (Jiménez et al. 2012) and thus does not have a free-slip lower boundary. Nonetheless, care was taken to select trajectories that remain above the lowest scalar model level, with the exception of trajectory 19. Trajectory 19 passes below the lowest scalar model level, but only slightly (maximum descent below the lowest scalar model level is $0.43 \mathrm{~m}$ ), thus we expect any error to be negligible. Our use of the MYNN 2.5-level TKE boundary layer scheme (Nakanishi and Niino 2006) also mitigates the concern of Markowski and Bryan (2016) in which vertical wind shear can be overestimated in simulations that include friction but do not resolve eddies in the boundary layer.

The vorticity budgets along each trajectory were inspected in tandem with trajectory locations. For the near-surface trajectories, the time tendency of the residual could best be explained by whether the trajectory was outside or underneath the anvil cover. The vertical black lines in Fig. 22 indicate when a trajectory passes underneath the anvil edge. For trajectories 8,14 , and 20 (Figs. 22a,b,d), the $x$ and $y$ residuals oppose the ambient northwestward orientation of the horizontal vorticity when the trajectory is outside of the anvil cover, and the model output horizontal vorticity decreases during this period. After the trajectory passes underneath the anvil, the accumulated residuals remain relatively constant or begin to tend toward an increasingly northwestward orientation of horizontal vorticity, meaning that the processes represented by the residual have weakened or reversed. Since the time tendency of the residual becomes small or changes sign after each parcel passes under the anvil, we surmise that differential vertical mixing between the full sun and the anvil-shaded regions drives the changes in the residual along these trajectories, consistent with a loss of horizontal vorticity with time in the sun where TKE values are larger, and relatively constant horizontal vorticity under the anvil where TKE values are lower (Fig. 20c).

Trajectory 19 (Fig. 22c) begins just outside of the anvil cover, and the residual remains relatively small until 1550 UTC (when it approaches the forward-flank gust front and storm-scale processes become dominant; similar for all trajectories), consistent with little vertical mixing. Further evidence that vertical mixing drives the residual while a trajectory is outside of the anvil is a brief stabilization in the residuals along trajectory 20 from 1418 to 1438 UTC (between the dashed lines in Fig. 22d). During this time, this trajectory passes through stabilized air from small leading convective cells, where vertical 

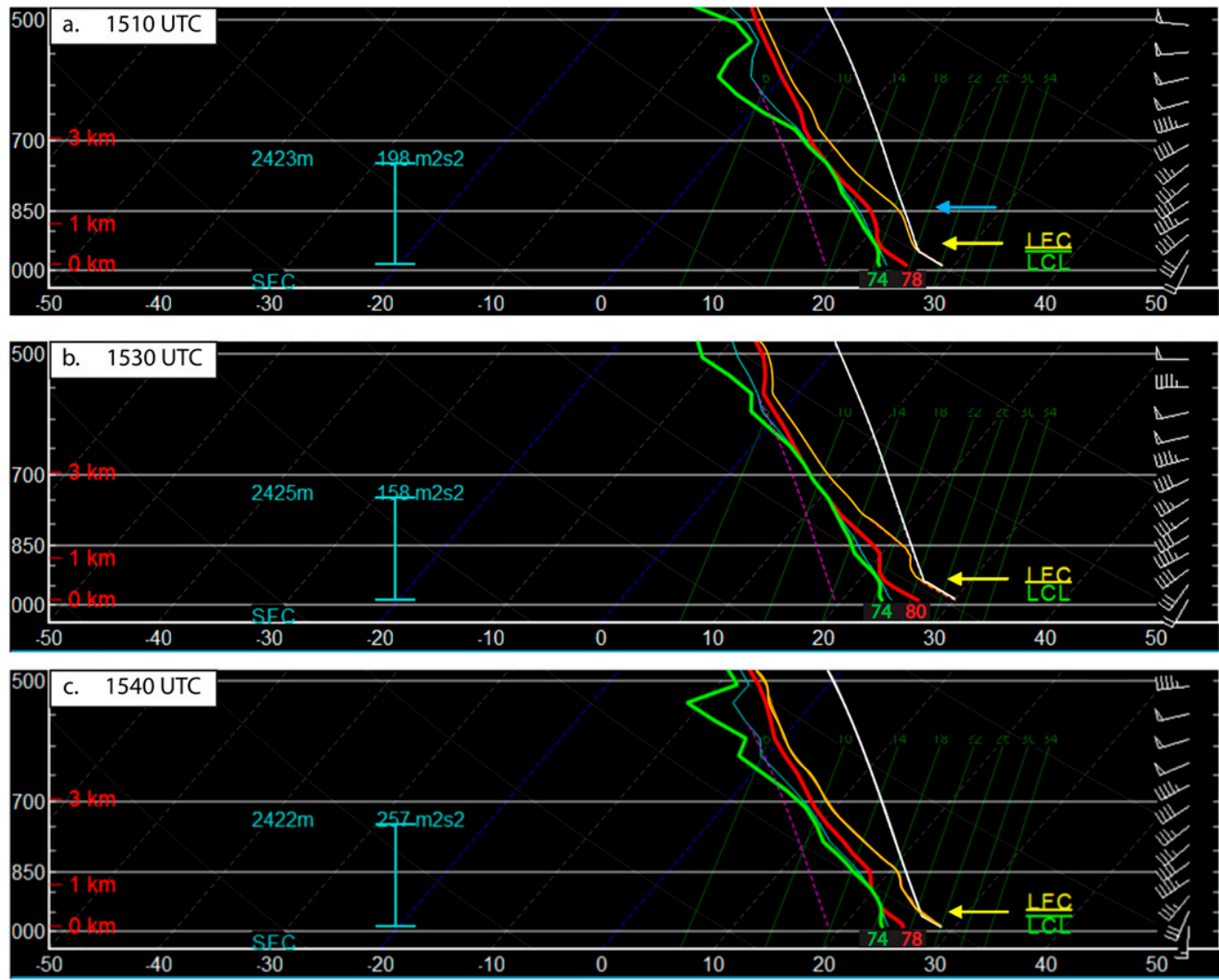

FIG. 18. Model soundings taken at (a) 1510 UTC from the location indicated in Fig. 17a, (b) 1530 UTC from the location indicated in Fig. 17b, and (c) 1540 UTC from the location under the anvil indicated in Fig. 20a. The white line is the most unstable parcel process curve and the orange line is the environmental virtual temperature. Yellow arrows indicate the LFC for an undilute surface parcel and the blue arrow in (a) is where an undilute surface parcel becomes significantly buoyant. Soundings were generated using SHARPpy (Blumberg et al. 2017).

mixing is less than in the environment outside of the anvil (e.g., see the reduced TKE near the cell south of the main anvil around $87.75^{\circ} \mathrm{W}$ in Fig. 20c).

The TKE along trajectories 4 and 5 exceeds $1.8 \mathrm{~m}^{2} \mathrm{~s}^{-2}$, indicating that mixing occurs along these trajectories (not shown), but the horizontal vorticity remains constant (Figs. 22e,f). These trajectories are between 880 and $1030 \mathrm{~m}$ MSL, however, where the horizontal winds are relatively uniform with height (Fig. 15a). Thus, mixing in an unsheared layer does not significantly alter the horizontal vorticity along these trajectories. The anvil-generated differential heating boundary was important to supercell development because it allowed for the preservation of the near-surface vertical wind shear and thus SRH (Figs. 20a,b) to its north via reduced vertical mixing (Fig. 20c). The observations and RAP analyses indicate that the differential heating boundary extended eastward from the elevated storms and that near-surface horizontal vorticity was also preserved to its north as in the simulation. The leading precipitation during 24 August 2016 may have also aided in preserving near-surface horizontal vorticity owing to stabilization by evaporative cooling (cluster 1 in Fig. 1a).

\section{e. Perturbation pressure analysis}

In section $4 \mathrm{c}$, we demonstrated that updrafts begin substantially ingesting surface air between 1550 and 1600 UTC and that updrafts and mesocyclones intensify after this occurs. In this section, we explore vertical accelerations owing to vertical perturbation pressure gradients during this transition period. Figure 9 reveals that APDN dominates the other contributions to the vertical perturbation pressure gradients at 1600 UTC, meaning that if accelerations owing to vertical perturbation pressure gradients aid in the development of surface-based updrafts, those due to the APDN term are likely the most important, possibly permitting near-surface air to ascend through a moist neutral layer (e.g., Fig. 18a).

Perturbation pressure decomposition is used to investigate a dissipating updraft and a persisting updraft 

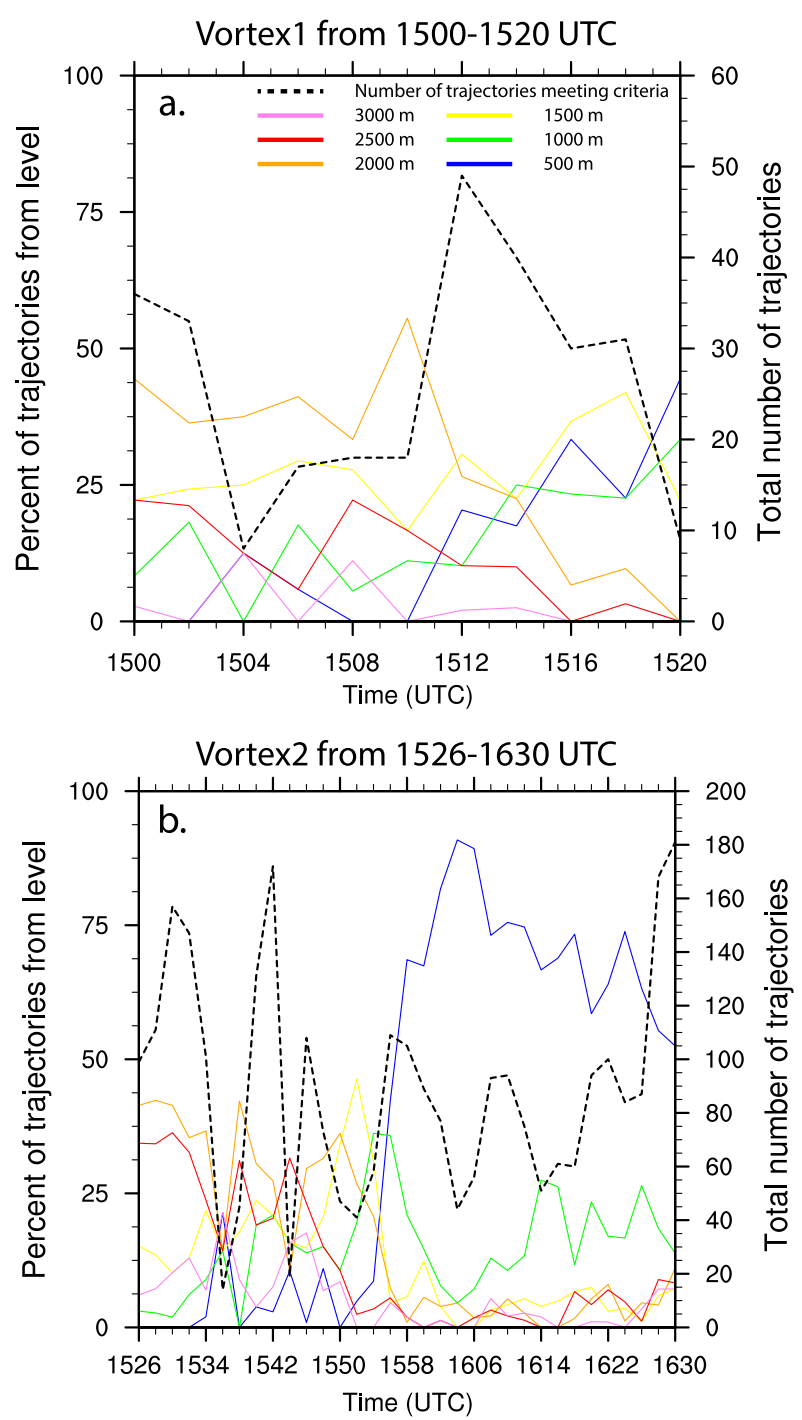

FIG. 19. Number of trajectories that ascend by at least $4 \mathrm{~km}$ over a 10 -min period within a $7 \mathrm{~km} \times 7 \mathrm{~km}$ box centered on the $1-\mathrm{km}$ maximum $\zeta$ (dashed black line) for (a) vortex 1 from 1500 to 1520 UTC, and the percentage of those trajectories that originate from 3000 (violet), 2500 (red), 2000 (orange), 1500 (yellow), 1000 (green), and $500 \mathrm{~m}$ MSL (blue). (b) As in (a), but for vortex 2 from 1526 to 1630 UTC.

associated with vortex 2. Positive (upward) APDN at $900 \mathrm{~m}$ is generally collocated with $\zeta$ at $2 \mathrm{~km}$ of either sign (Fig. 23). An updraft is present from 1546 to 1550 UTC (blue arrows in Figs. 14c and 23a,b), but it does not persist. At 1552 UTC, a new updraft develops in an area of upward APDN at $900 \mathrm{~m}$ (red arrows in Figs. $14 \mathrm{c}$ and 23b,c). This updraft strengthens from 1552 to 1600 UTC (Figs. 13 and 23c,d) as vortex 2 acquires $\zeta>0.015 \mathrm{~s}^{-1}$ at $1 \mathrm{~km}$ (Figs. 13 and 14d) and is the first updraft ingesting mostly near-surface air (Figs. 16d, 19b, and 21).
The blue lines in Figs. 23a,b correspond to the southnorth vertical cross sections in Figs. 24a,c and are taken through the updraft that dissipates. Figure 24a indicates that $\zeta$ is greater than $0.01 \mathrm{~s}^{-1}$ near $1 \mathrm{~km}$, but that there is little $\zeta$ above this level, inducing negative APDN in this updraft from 1.5 to $5 \mathrm{~km}$ at 1546 UTC. By 1550 UTC (Fig. 24c), this updraft weakens between 1.5 and $3 \mathrm{~km}$, consistent with negative APDN in this layer. This appears to be a failed surface-based convective initiation attempt.

During this same time period, a new updraft develops southwest of the dissipating updraft discussed above. Vertical cross sections through this developing updraft are indicated by the red lines in Figs. 23a,b,d. At 1546 UTC (Fig. 24b), before the updraft at $1 \mathrm{~km}$ is stronger than $5 \mathrm{~m} \mathrm{~s}^{-1}$, there is an elevated updraft above $3 \mathrm{~km}$ collocated with $\zeta>0.01 \mathrm{~s}^{-1}$, yielding positive APDN extending from near the surface to $4.5 \mathrm{~km}$. The rotation in this elevated updraft is obtained by ingestion of weakly sheared air from 1.0 to $1.3 \mathrm{~km}$ (Figs. 15a, 16b, and 19b). An area of weak convergence (not shown) initiates this updraft as parcels at this level require little lifting to reach their LFC (Fig. 18b). This updraft builds downward through 1550 UTC (Figs. 14c and 24d) and moves atop vortex 2 (partially seen in Fig. $24 \mathrm{~d}$ at $y=20 \mathrm{~km})$.

The vertical cross sections in Figs. 24e,f are taken along the red line in Fig. 23d. The cross section of APDN at 1600 UTC (Fig. 24e) illustrates upward accelerations greater than $0.10 \mathrm{~m} \mathrm{~s}^{-2}$ in the surface-3-km layer, over roughly the bottom half of the updraft. Above this layer, in the top half of the updraft, APDN is negative and of similar magnitude. Large negative APDN is generally not indicative of updraft growth, but this updraft intensifies to $20 \mathrm{~m} \mathrm{~s}^{-1}$ by 1600 UTC (Fig. 24e). APDL was also inspected and is an order of magnitude smaller than APDN (e.g., Fig. 9), suggesting that updraft growth is not primarily driven by APDL. APB, however, can be of similar magnitude to APDN (McCaul and Weisman 1996; Figs. 9 and 24f) and positive APB is collocated with negative APDN (Figs. 24e,f), offsetting the downward acceleration from APDN, allowing the updraft to persist and even deepen when $\zeta$ near the surface becomes stronger than $\zeta$ aloft. Dawson et al. (2016) found a similar result within a tornado-like vortex. The strengthening updraft can then further increase $\zeta$ through stretching.

This analysis suggests that the first persistent surfacebased updraft is at least partially a result of positive APDN developing below rotation around $5 \mathrm{~km}$ MSL. Once the updraft is established and ingesting surface air by 1600 UTC, tilting and stretching increase the lowlevel $\zeta$ rapidly such that large negative APDN exists in 


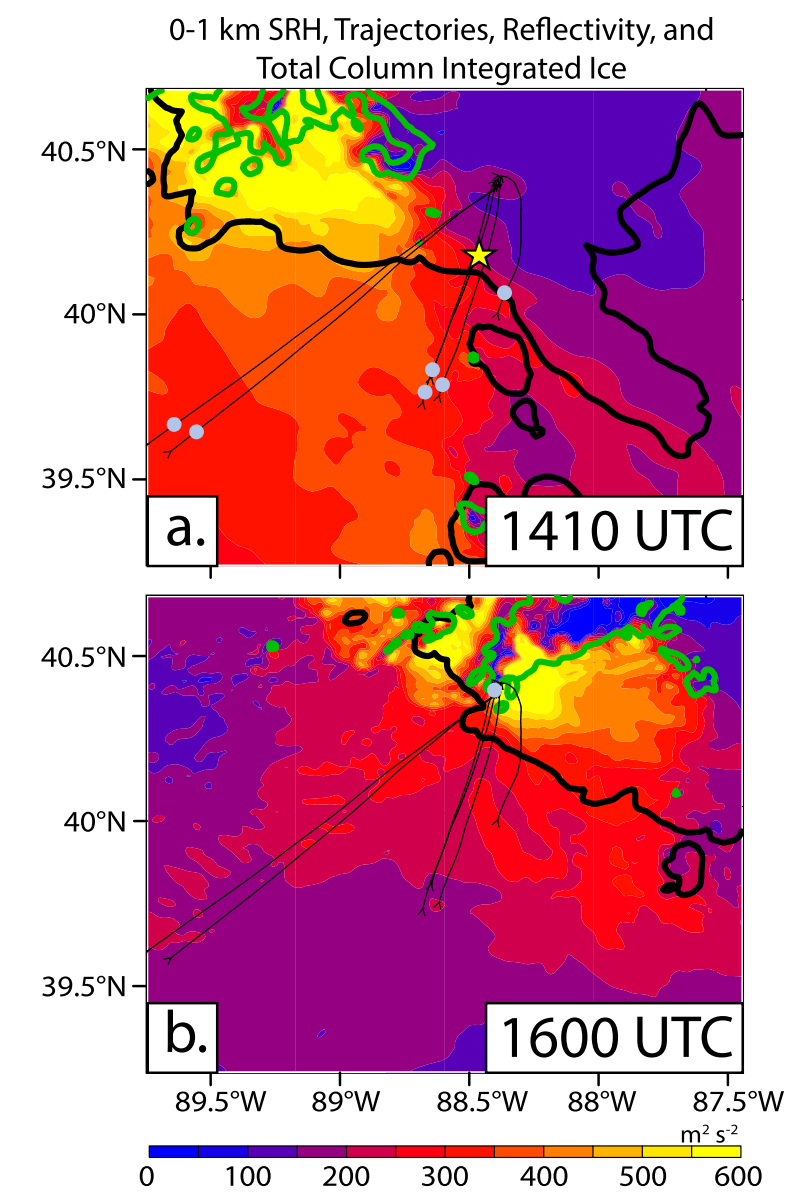

TKE, Reflectivity, Total Column Integrated Ice, Horizontal Vorticity, and Storm-Relative Wind

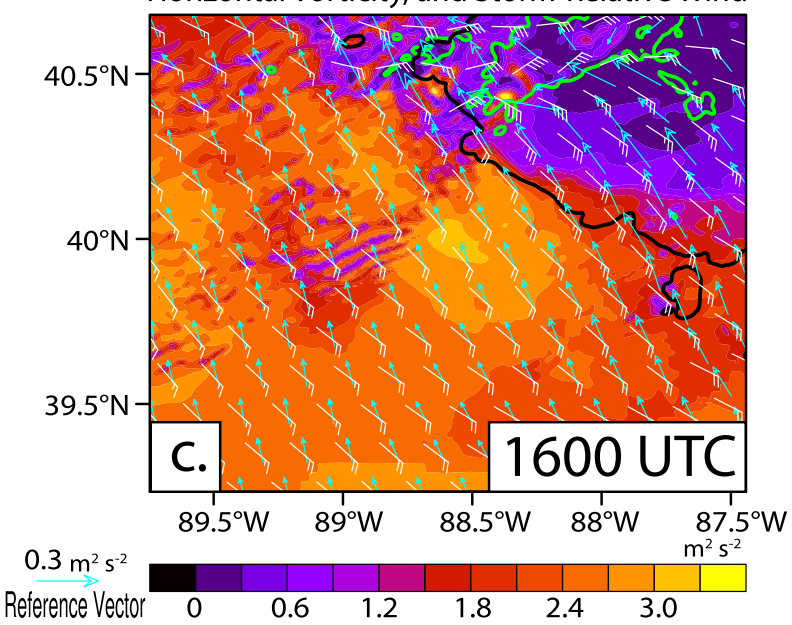

FIG. 20. 0-1-km SRH ( $\mathrm{m}^{2} \mathrm{~s}^{-2}$; shaded), 40-dBZ simulated reflectivity contour at $1 \mathrm{~km}$ (green), and total column integrated ice of $0.1 \mathrm{~kg} \mathrm{~m}^{-2}$ (thick black contour) at (a) 1410 and (b) 1600 UTC. Thin black lines are trajectories bound for the strongest $1 \mathrm{~km}$ MSL updraft at 1600 UTC in Fig. $14 \mathrm{~d}$ and gray dots are parcel locations along each trajectory. Trajectory heights are provided in Fig. 21. The star in (a) is the location of the sounding in Fig. 18c. (c) TKE at $25 \mathrm{~m}$ AGL $\left(\mathrm{m}^{2} \mathrm{~s}^{-2}\right.$; shaded), 1-km simulated reflectivity $(40 \mathrm{dBZ}$, green), total column integrated ice

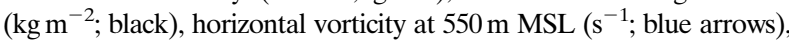
and storm-relative winds at $550 \mathrm{~m}$ MSL (kt; white barbs) at 1600 UTC.

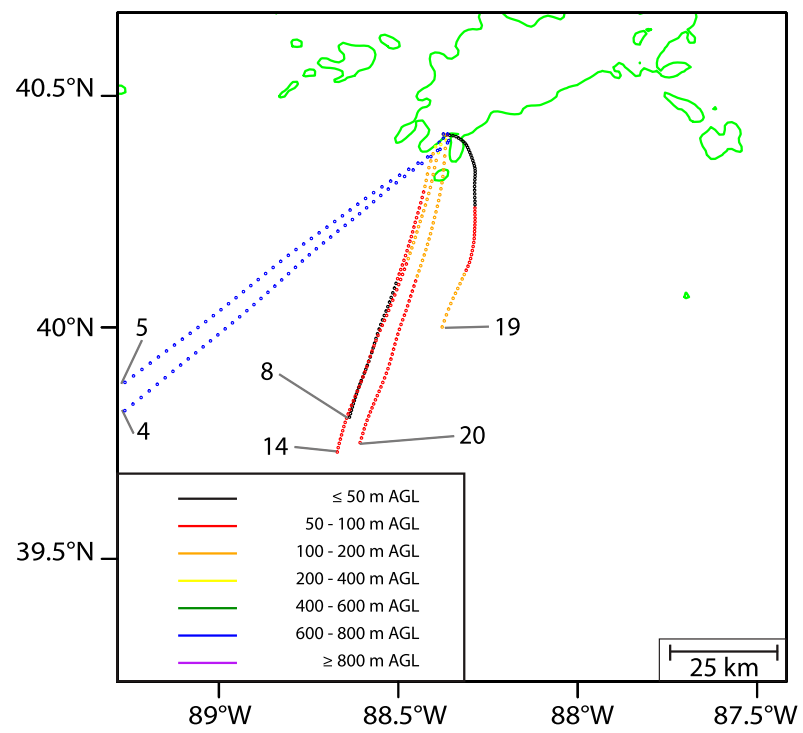

FIG. 21. Selected inflow trajectories that are within the $1-\mathrm{km}$ updraft at 1600 UTC. Trajectories are labeled with their trajectory number and the colored dots represent trajectory height (m AGL) at each 2-min interval along the trajectory. The 40-dBZ simulated reflectivity contour at $1 \mathrm{~km}$ (green) at 1600 UTC is provided for reference.

the top half of the updraft, which is offset by positive APB in the same area.

Only $0.01 \mathrm{~s}^{-1}$ of $\zeta$ at $5 \mathrm{~km}$ MSL was needed to initiate this process in the simulation (Fig. 24b), making it plausible that if an elevated updraft ingests a small amount of air from around $1 \mathrm{~km}$ (Figs. 15a and 16b,c), sufficient $\zeta$ could develop aloft and aid in the development of a surface-based updraft through APDN. Although solar heating increases CAPE and reduces CIN, this occurs less rapidly in the anvil-shaded region. Thus, accelerations owing to dynamic pressure perturbations may have been particularly important here in allowing near-surface parcels to reach their LFC.

\section{Conclusions}

On 24 August 2016, unorganized elevated convection developed into three discrete, surface-based supercells, each of which produced multiple tornadoes across Indiana and Ohio. That morning, two clusters of elevated storms developed over Illinois and a differential heating boundary formed owing to cloud shading from the leading cluster. The updrafts in the trailing cluster exhibited only weak, transient rotation while they were elevated, as there was little vertical wind shear in their inflow layer. As these storms began to ingest highly sheared near-surface air, they acquired rotation through tilting and subsequent stretching of vorticity. Each supercell formed and produced a significant tornado in 

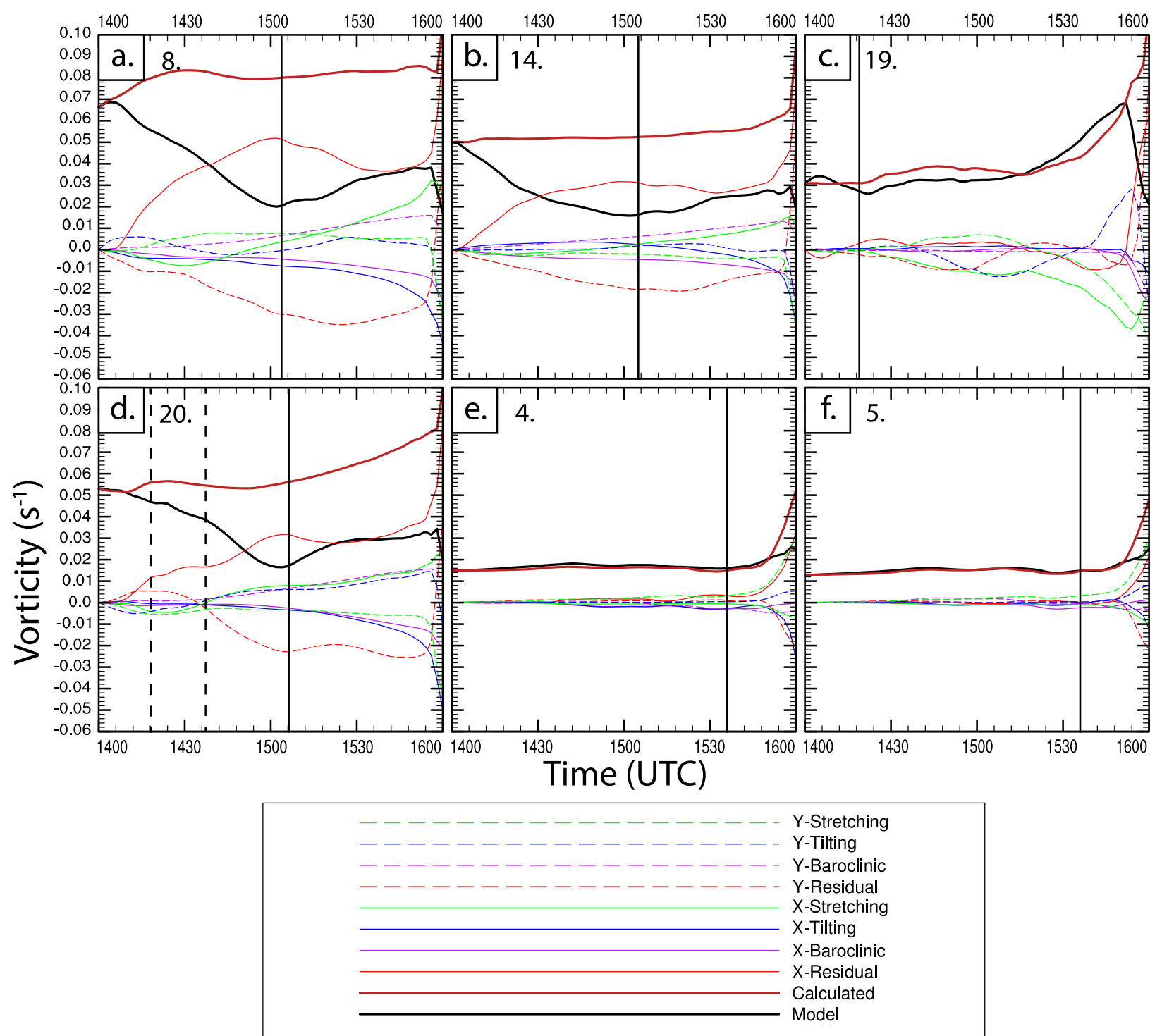

FIG. 22. Integrated budgets of the $x$ component (solid) and $y$ component (dashed) of vorticity. Shown are stretching (green), tilting (blue), and baroclinic generation (purple) of horizontal vorticity along selected trajectories. The sum of stretching, tilting, and baroclinic generation is given by the calculated (thick brown) lines, and the model output horizontal vorticity is given by the thick black lines. The residual (red) is the calculated horizontal vorticity subtracted from the model output horizontal vorticity for each component. Budgets displayed are calculated along trajectories (a) 8, (b) 14, (c) 19, (d) 20, (e) 4, and (f) 5, where (a)-(d) are the near-surface inflow trajectories in Fig. 21 and (e) and (f) are the inflow trajectories above the strongly sheared layer in Fig. 21. Vertical black lines indicate when each trajectory enters underneath the anvil. Dashed lines in (d) indicate the time period when trajectory 20 was within convectively stabilized air.

the vicinity of the northeastward-moving differential heating boundary, while an MCV owing to convection from the previous evening provided sufficient $0-6-\mathrm{km}$ bulk wind shear for supercell development.

A WRF Model simulation accurately captures these features, including the MCV and the differential heating boundary. The simulation only depicts one initial cluster of elevated storms, however, which becomes a single surface-based supercell. Vertical cross sections showcase multiple elevated cells in the simulation before 1530 UTC, and that the storms begin ingesting near-surface air between 1550 and 1600 UTC. After this time, the updrafts become stronger and deeper until one deep, rotating updraft develops by 1630 UTC. The simulation reveals that the transition from disorganized elevated convection to a surface-based supercell is not instantaneous in this case, but that a few attempts at surface-based convection initiation occur before a dominant rotating updraft develops. 
1 km APDN, 1 km Vertical Velocity, and 2 km Relative Vertical Vorticity
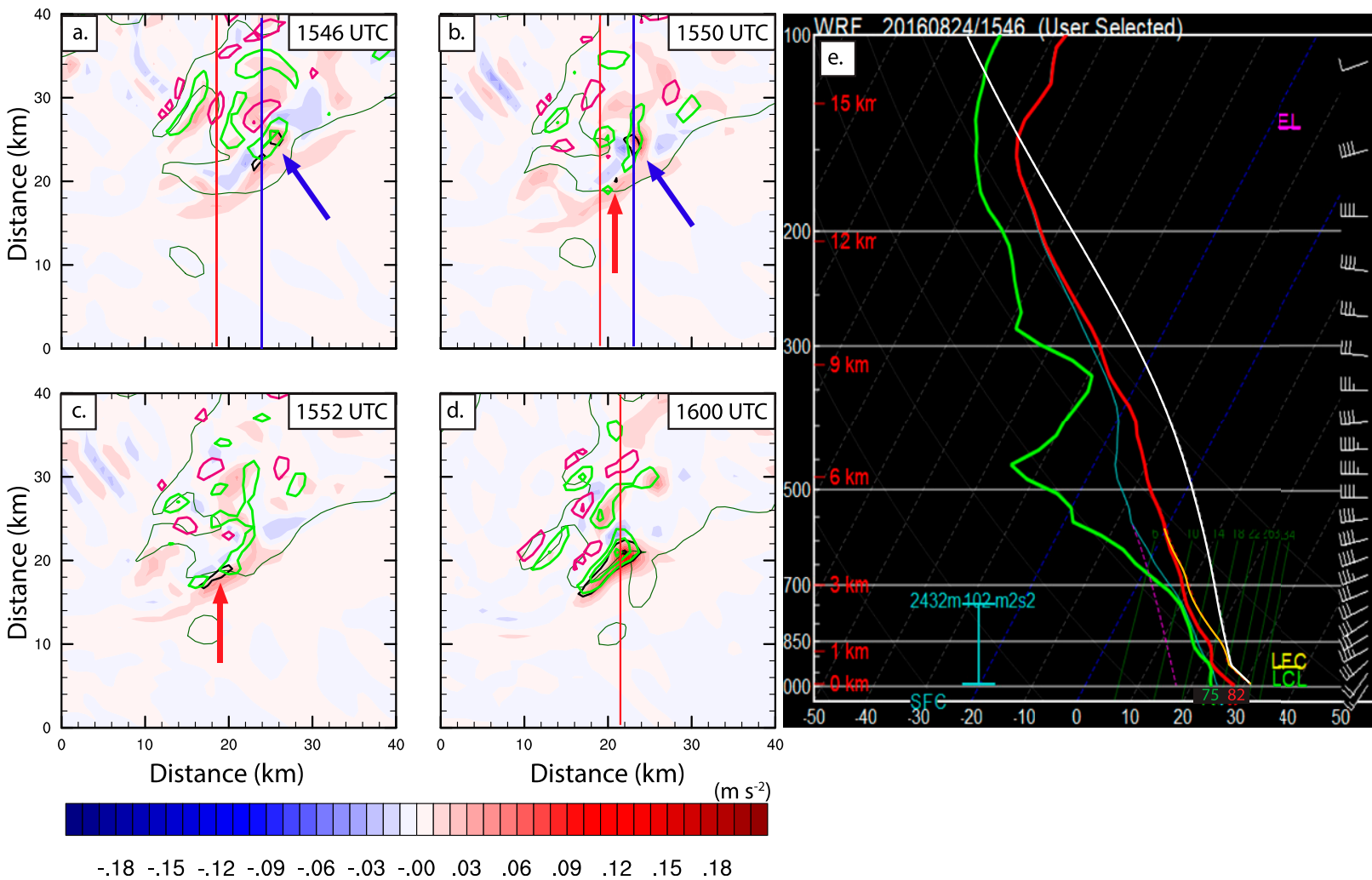

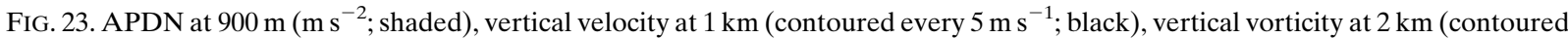
every $0.005 \mathrm{~s}^{-1}$; positive values in green, negative values in pink, and zero contour suppressed for clarity), and 40 -dBZ simulated reflectivity contour at $1 \mathrm{~km}$ (thin dark green line) at (a) 1546, (b) 1550, (c) 1552, and (d) 1600 UTC. Blue lines in (a) and (b) are the locations of the vertical cross sections in Figs. 24a and 24c. Red lines are the locations of the vertical cross sections in Figs. 24b and 24d-f (cross sections in Figs. 24e,f are identical). The blue arrows in (a) and (b) indicate the updraft that dissipates and the red arrows in (b) and (c) indicate the updraft that persists. The numbers on the $x$ and $y$ axes are provided as a scale of distance; the location differs from panel to panel. (e) Base-state sounding used for the perturbation pressure decomposition at 1546 UTC. The white line is the most unstable parcel process curve, and the orange line is the environmental virtual temperature.

Trajectories confirm that the updrafts begin ingesting near-surface air during this period. Soundings taken along trajectories indicate the presence of a moist neutral layer from 950 to $850 \mathrm{hPa}$, meaning that parcels do not become significantly buoyant until above $850 \mathrm{hPa}$. As solar heating increases parcel buoyancy in the moist neutral layer, more parcels from the $0-1-\mathrm{km}$ layer enter the updrafts.

The observed differential heating boundary originated from cloud shading associated with cluster 1 . In the simulation, the differential heating boundary also originates from cloud shading, but from the supercell anvil. Back trajectories illustrate that near-surface parcels within the updrafts pass through the cloudshaded region while vorticity budgets along those trajectories indicate that the cloud cover preserves horizontal vorticity by reducing vertical mixing near the surface. This analysis is consistent with the observed supercells developing and all significant tornadoes occurring in the vicinity of the differential heating boundary. Future work may include repeating the simulation without the effects of cloud shading, as in Frame and Markowski (2013).

The WRF Model output was interpolated to flat vertical levels to perform a perturbation pressure decomposition. This methodology required a sensitivity test of the vertical perturbation pressure gradient accelerations to the location of the base state because the initial environment in this simulation is horizontally inhomogeneous. The APDL is the most sensitive to the location of the base state, but contributes less than $10 \%$ to the APTD in this environment. Both APB and APDN exhibit a standard deviation approximately an order of magnitude less than their means, indicating little sensitivity to the base-state location.

The development of vertical perturbation pressure gradient accelerations likely aids surface parcels, particularly those near and north of the differential heating 


\section{Vertical Cross Sections of Vertical Velocity, Vertical Vorticity, and Perturbation Pressure Accelerations}
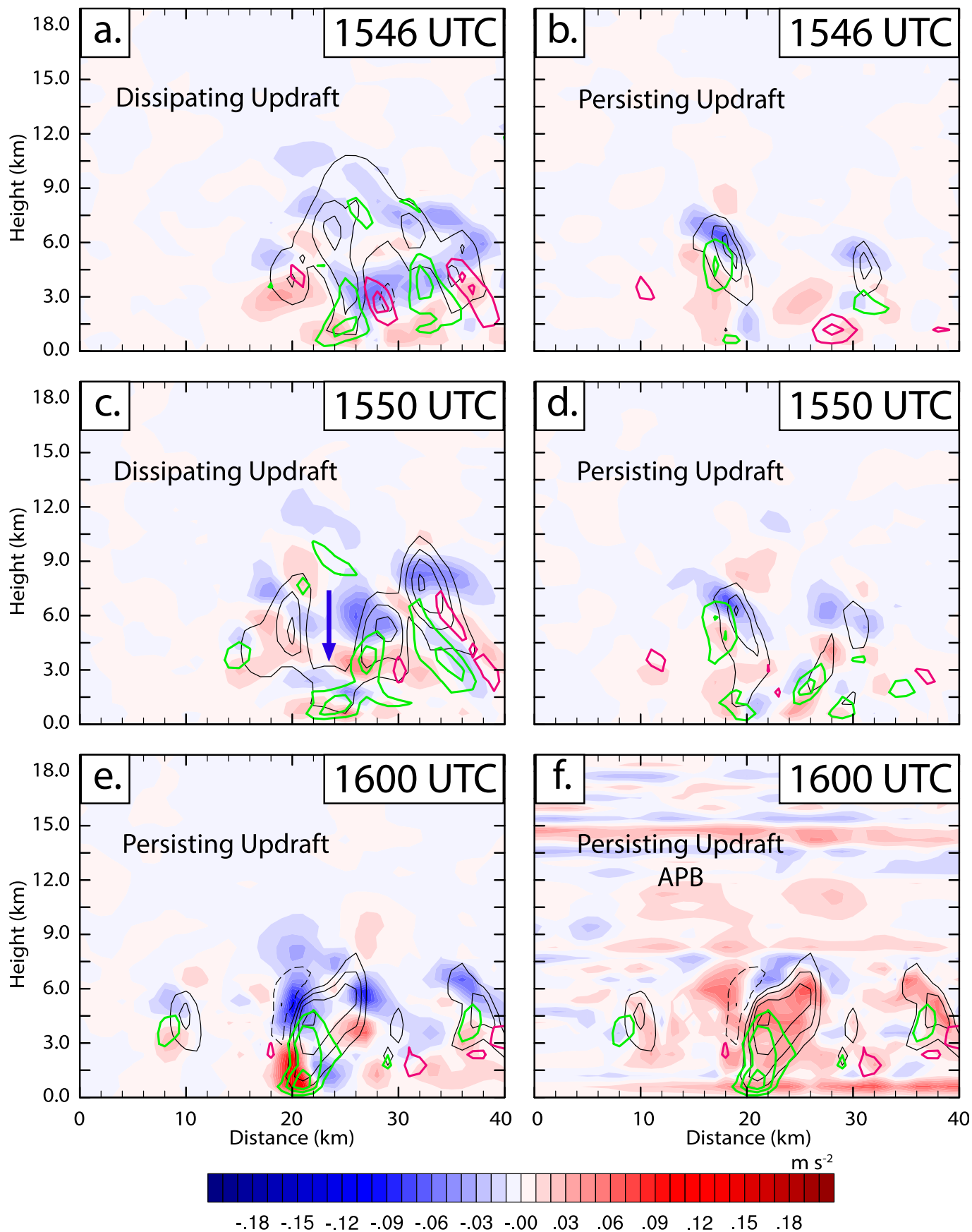

FIG. 24. South-north vertical cross sections of APDN ( $\mathrm{m} \mathrm{s}^{-2}$; shaded), vertical velocity (contoured every $5 \mathrm{~m} \mathrm{~s}^{-1}$; black), and vertical vorticity (contoured every $0.005 \mathrm{~s}^{-1}$; positive values in green, negative values in pink, and zero contour suppressed for clarity) along the blue and red lines in Fig. 23 at (a),(b) 1546, (c),(d) 1550, and (e) 1600 UTC. (f) As in (e), but with APB ( $\mathrm{m} \mathrm{s}^{-2}$; shaded). The blue arrow in (c) indicates the updraft that dissipates. The numbers along the $x$ axes indicate the south-north distance along each cross section. 
boundary, in overcoming the lack of significant buoyancy in the moist neutral layer just above their LFC. The perturbation pressure decomposition indicates that $\zeta$ acquired in elevated updrafts leads to positive APDN below the level of maximum rotation. As developing updrafts ingest more strongly sheared near-surface air, $\zeta$ increases and APDN becomes downward directed above the strongest rotation. In updrafts that persist, the negative APDN is offset by positive APB, allowing the updraft to grow, strengthen, and further stretch $\zeta$. In updrafts that do not persist, upward-directed APB does not offset the downward APDN.

In this case, air from the lowest few $100 \mathrm{~m}$ AGL needed to be ingested by updrafts for significant rotation to form because this was the only layer where significant vertical wind shear existed. In environments where convection occurs above a weakly stable but strongly sheared near-surface layer, the development of weak rotation aloft can permit upward-directed nonlinear dynamic perturbation pressure accelerations to form and allow for more of the helicity-rich nearsurface air to enter the updrafts, and an intense rotating updraft may develop shortly afterward. The environment on 24 August 2016 was also quite moist, limiting the evaporative cooling potential in downdrafts and the production of surging outflow. If the initial storms had been more outflow dominant, it is possible that they would not have become supercells at all.

An important takeaway from this event is that environments favorable for supercells and tornadoes should not necessarily be discounted if convectionallowing models do not depict cellular convection, particularly if any ongoing convection is not outflow dominant or is poorly initialized. The analysis of observations in real time, specifically the identification of boundaries such as the differential heating boundary, is crucial for a better qualitative understanding of an environment. Despite this challenging forecast, we are especially grateful for the hard work and dedication of numerous operational and broadcast meteorologists who delivered timely and accurate warnings to the public during a tornado outbreak that occurred with little advance notice. Their efforts prevented any storm-related fatalities during this outbreak and are commended.

Acknowledgments. We are grateful to the University of Illinois Department of Atmospheric Sciences for financial support. The authors thank the following from the University of Illinois Department of Atmospheric Sciences: Prof. Steve Nesbitt and Dr. Brian Jewett for assistance with running WRF and the Read/Interpolate/Plot program, Prof. Jeff Trapp and
Geoff Marion for providing the perturbation pressure decomposition code, Prof. Francina Dominguez for help with statistics, and David Wojtowicz and Dr. Ken Patten for technical support. We also thank Manda Chasteen (University of Oklahoma) for assistance with WRF Model configuration and Zachary Hargrove (NWS Bismarck, North Dakota) for providing NCL scripts for post-processing model output. We are also grateful for discussions with Roger Edwards (SPC) and Brian Curran (NWS Midland/Odessa, Texas) that helped inspire this work. We finally thank three anonymous reviewers and Chief Editor Prof. Gary Lackmann, whose constructive comments improved this work. Radar figures were produced using GR2Analyst, tornado track figures were produced using QGIS, and model sounding figures were produced using SHARPpy.

\section{REFERENCES}

Atkins, N. T., and M. St. Laurent, 2009: Bow echo mesovortices. Part I: Processes that influence their damaging potential. Mon. Wea. Rev., 137, 1497-1513, https://doi.org/10.1175/ 2008MWR2649.1.

Benjamin, S. G., and Coauthors, 2016: A North American hourly assimilation and model forecast cycle: The Rapid Refresh. Mon. Wea. Rev., 144, 1669-1694, https://doi.org/ 10.1175/MWR-D-15-0242.1.

Bluestein, H. B., and M. L. Weisman, 2000: The interaction of numerically simulated supercells initiated along lines. Mon. Wea. Rev., 128, 3128-3149, https://doi.org/10.1175/15200493(2000) $128<3128$ :TIONSS $>2.0$. CO;2.

Blumberg, W. G., K. T. Halbert, T. A. Supinie, P. T. Marsh, R. L. Thompson, and J. A. Hart, 2017: SHARPpy: An open-source sounding analysis toolkit for the atmospheric sciences. Bull. Amer. Meteor. Soc., 98, 1625-1636, https://doi.org/10.1175/ BAMS-D-15-00309.1.

Brooks, H. E., C. A. Doswell III, and J. Cooper, 1994: On the environments of tornadic and nontornadic mesocyclones. Wea. Forecasting, 9, 606-618, https://doi.org/10.1175/15200434(1994)009<0606:OTEOTA > 2.0.CO;2.

Burgess, D. W., and E. B. Curran, 1985: The relationship of storm type to environment in Oklahoma on 26 April 1984. Preprints, 14th Conf. on Severe Local Storms, Indianapolis, IN, Amer. Meteor. Soc., 208-211.

Coffer, B. E., and M. D. Parker, 2015: Impacts of increasing lowlevel shear on supercells during the early evening transition. Mon. Wea. Rev., 143, 1945-1969, https://doi.org/ 10.1175/MWR-D-14-00328.1.

, and _ 2017: Simulated supercells in nontornadic and tornadic VORTEX2 environments. Mon. Wea. Rev., 145, 149180, https://doi.org/10.1175/MWR-D-16-0226.1.

Davies-Jones, R., 1984: Streamwise vorticity: The origin of updraft rotation in supercell thunderstorms. J. Atmos. Sci., 41, 2991-3006, https://doi.org/10.1175/1520-0469(1984)041<2991: SVTOOU $>2.0 . \mathrm{CO} ; 2$.

Dawson, D. T., M. Xue, A. Shapiro, J. A. Milbrandt, and A. D. Schenkman, 2016: Sensitivity of real-data simulations of the 3 May 1999 Oklahoma City tornadic supercell and associated tornadoes to multimoment microphysics. Part II: Analysis of buoyancy and dynamic pressure forces in simulated 
tornado-like vortices. J. Atmos. Sci., 73, 1039-1061, https:// doi.org/10.1175/JAS-D-15-0114.1.

Doswell, C. A., III, and P. M. Markowski, 2004: Is buoyancy a relative quantity? Mon. Wea. Rev., 132, 853-863, https:// doi.org/10.1175/1520-0493(2004)132<0853:IBARQ>2.0.CO; 2.

Finley, C. A., W. R. Cotton, and R. A. Pielke Sr., 2001: Numerical simulation of tornadogenesis in a high-precipitation supercell. Part I: Storm evolution and transition into a bow echo. J. Atmos. Sci., 58, 1597-1629, https://doi.org/10.1175/15200469(2001)058<1597:NSOTIA $>2.0$.CO;2.

Frame, J. W., and P. M. Markowski, 2010: Numerical simulations of radiative cooling beneath the anvils of supercell thunderstorms. Mon. Wea. Rev., 138, 3024-3047, https://doi.org/ 10.1175/2010MWR3177.1.

— simulated supercell thunderstorms. Mon. Wea. Rev., 141, 2802-2820, https://doi.org/10.1175/MWR-D-12-00146.1.

— ment of storms and transition to supercells during the Indiana and Ohio tornado outbreak of 24 August 2016. 29th Conf. on Severe Local Storms, Stowe, VT, Amer. Meteor. Soc., P190, https:// ams.confex.com/ams/29SLS/webprogram/Paper348222.html.

French, J., and M. D. Parker, 2010: The response of simulated nocturnal convective systems to a developing low-level jet. J. Atmos. Sci., 67, 3384-3408, https://doi.org/10.1175/ 2010JAS3329.1.

Geerts, B., and Coauthors, 2017: The 2015 Plains Elevated Convection at Night field project. Bull. Amer. Meteor. Soc., 98, 767-786, https://doi.org/10.1175/BAMS-D-15-00257.1.

Gropp, M. E., and C. E. Davenport, 2018: The impact of the nocturnal transition on the lifetime and evolution of supercell thunderstorms in the Great Plains. Wea. Forecasting, 33, 10451061, https://doi.org/10.1175/WAF-D-17-0150.1.

Guchte, A. V., and J. M. L. Dahl, 2018: Sensitivities of parcel trajectories beneath the lowest scalar model level of a Lorenz vertical grid. Mon. Wea. Rev., 146, 1427-1435, https://doi.org/ 10.1175/MWR-D-17-0190.1.

Hane, C. E., J. D. Watts, D. L. Andra, J. A. Haynes, E. Berry, R. M. Rabin, and F. H. Carr, 2003: The evolution of morning convective systems over the U.S. Great Plains during the warm season. Part I: The forecast problem. Wea. Forecasting, 18, 1286-1294, https://doi.org/10.1175/1520-0434(2003)018<1286: TEOMCS $>2.0 . \mathrm{CO} ; 2$.

— J. A. Haynes, D. L. Andra, and F. H. Carr, 2008: The evolution of morning convective systems over the U.S. Great Plains during the warm season. Part II: A climatology and the influence of environmental factors. Mon. Wea. Rev., 136, 929944, https://doi.org/10.1175/2007MWR2016.1.

Iacono, M. J., E. J. Mlawer, S. A. Clough, and J.-J. Morcrette, 2000: Impact of an improved longwave radiation model, RRTM, on the energy budget and thermodynamic properties of the NCAR Community Climate Model, CCM3. J. Geophys. Res., 105, 14 873-14 890, https://doi.org/10.1029/ 2000JD900091.

Jiménez, P. A., J. Dudhia, J. F. González-Rouco, J. Navarro, J. P. Montávez, and E. García-Bustamante, 2012: A revised scheme for the WRF surface layer formulation. Mon. Wea. Rev., 140, 898-918, https://doi.org/10.1175/MWR-D-11-00056.1.

Klemp, J. B., and R. B. Wilhelmson, 1978: The simulation of threedimensional convective storm dynamics. J. Atmos. Sci., 35, 1070-1096, https://doi.org/10.1175/1520-0469(1978)035<1070: TSOTDC $>2.0 . \mathrm{CO} ; 2$.
- and R. Rotunno, 1983: A study of the tornadic region within a supercell thunderstorm. J. Atmos. Sci., 40, 359-377, https:// doi.org/10.1175/1520-0469(1983)040<0359:ASOTTR>2.0.CO;2.

Lilly, D. K., 1986: The structure, energetics and propagation of rotating convective storms. Part II: Helicity and storm stabilization. J. Atmos. Sci., 43, 126-140, https://doi.org/10.1175/ 1520-0469(1986)043<0126:TSEAPO > 2.0.CO;2.

Livneh, B., P. J. Restrepo, and D. P. Lettenmaier, 2011: Development of a unified land model for prediction of surface hydrology and land-atmosphere interactions. J. Hydrometeor., 12, 1299-1320, https://doi.org/10.1175/2011JHM1361.1.

Markowski, P. M., and Y. P. Richardson, 2014: The influence of environmental low-level shear and cold pools on tornadogenesis: Insights from idealized simulations. J. Atmos. Sci., 71, 243-275, https://doi.org/10.1175/JAS-D-13-0159.1.

— potential problem for convective storm simulations. Mon. Wea. Rev., 144, 1841-1850, https://doi.org/10.1175/MWR-D15-0439.1.

__ E. E. Rasmussen, J. M. Straka, and D. C. Dowell, 1998a: Observations of low-level baroclinity generated by anvil shadows. Mon. Wea. Rev., 126, 2942-2958, https://doi.org/ 10.1175/1520-0493(1998)126<2942:OOLLBG > 2.0.CO;2.

,$- \ldots$, and 1998b: The occurrence of tornadoes in supercells interacting with boundaries during VORTEX-95. Wea. Forecasting, 13, 852-859, https://doi.org/10.1175/15200434(1998)013<0852:TOOTIS > 2.0.CO;2.

Marquis, J. N., Y. P. Richardson, P. Markowski, D. Dowell, J. Wurman, and K. Kosiba, 2016: An investigation of the Goshen County, Wyoming, tornadic supercell of 5 June 2009 using EnKF assimilation of mobile mesonet and radar observations collected during VORTEX2. Part II: Mesocyclonescale processes affecting tornado formation, maintenance, and decay. Mon. Wea. Rev., 144, 3441-3463, https://doi.org/ 10.1175/MWR-D-15-0411.1.

Marsham, J. H., S. B. Trier, T. M. Weckwerth, and J. W. Wilson, 2011: Observations of elevated convection initiation leading to a surface-based squall line during 13 June IHOP_2002. Mon. Wea. Rev., 139, 247-271, https://doi.org/10.1175/ 2010MWR3422.1.

McCaul, E. W., and M. L. Weisman, 1996: Simulation of shallow supercell storms in landfalling hurricane environments. Mon. Wea. Rev., 124, 408-429, https://doi.org/10.1175/15200493(1996)124<0408:SOSSSI>2.0.CO;2.

Milbrandt, J. A., and M. K. Yau, 2005: A multimoment bulk microphysics parameterization. Part I: Analysis of the role of the spectral shape parameter. J. Atmos. Sci., 62, 3051-3064, https://doi.org/10.1175/JAS3534.1.

Mlawer, E. J., S. J. Taubman, P. D. Brown, M. J. Iacono, and S. A. Clough, 1997: Radiative transfer for inhomogeneous atmospheres: RRTM, a validated correlated-k model for the longwave. J. Geophys. Res., 102, 16 663-16 682, https://doi.org/ 10.1029/97JD00237.

Morrison, H., 2016: Impacts of updraft size and dimensionality on the perturbation pressure and vertical velocity in cumulus convection. Part II: Comparison of theoretical and numerical solutions and fully dynamical simulations. J. Atmos. Sci., 73, 1455-1480, https://doi.org/10.1175/JASD-15-0041.1.

— , and J. Milbrandt, 2011: Comparison of two-moment bulk microphysics schemes in idealized supercell thunderstorm simulations. Mon. Wea. Rev., 139, 1103-1130, https://doi.org/ 10.1175/2010MWR3433.1. 
Nakanishi, M., and H. Niino, 2006: An improved Mellor-Yamada level-3 model: Its numerical stability and application to a regional prediction of advection fog. Bound.-Layer Meteor., 119, 397-407, https://doi.org/10.1007/s10546-005-9030-8.

NCDC, 2016: Storm Data. Vol. 58, No. 8, 533 pp.

Nowotarski, C. J., P. M. Markowski, Y. P. Richardson, and G. H. Bryan, 2015: Supercell low-level mesocyclones in simulations with a sheared convective boundary layer. Mon. Wea. Rev., 143, 272-297, https://doi.org/10.1175/MWR-D-14-00151.1.

Parker, M. D., 2008: Response of simulated squall lines to low-level cooling. J. Atmos. Sci., 65, 1323-1341, https://doi.org/10.1175/ 2007JAS2507.1.

— 2014: Composite VORTEX2 supercell environments from near-storm soundings. Mon. Wea. Rev., 142, 508-529, https:// doi.org/10.1175/MWR-D-13-00167.1.

Rasmussen, E. N., S. Richardson, J. M. Straka, P. M. Markowski, and D. O. Blanchard, 2000: The association of significant tornadoes with a baroclinic boundary on 2 June 1995. Mon. Wea. Rev., 128, 174-191, https://doi.org/10.1175/1520-0493(2000)128<0174: TAOSTW $>2.0 . \mathrm{CO} ; 2$.

Rosenow, A. A., K. Howard, and J. Meitín, 2018: Gap-filling mobile radar observations of a snow squall in the San Luis Valley. Mon. Wea. Rev., 146, 2469-2481, https://doi.org/ 10.1175/MWR-D-17-0323.1.

Rotunno, R., and J. B. Klemp, 1982: The influence of the shearinduced pressure gradient on thunderstorm motion. Mon. Wea. Rev., 110,136-151, https://doi.org/10.1175/1520-0493(1982) $110<0136$ :TIOTSI $>2.0 . \mathrm{CO} ; 2$.

Schumacher, R. S., and R. H. Johnson, 2008: Mesoscale processes contributing to extreme rainfall in a midlatitude warm-season flash flood. Mon. Wea. Rev., 136, 3964-3986, https://doi.org/ 10.1175/2008MWR2471.1.

Sills, D., E. Hong, A. Jaffe, S. Stevenson, and G. A. Kopp, 2018: The 'cross-border' tornado outbreak of 24 August 2016Analysis of the two tornadoes in Ontario. 29th Conf. on Severe Local Storms, Stowe, VT, Amer. Meteor. Soc., P180, https:// ams.confex.com/ams/29SLS/webprogram/Paper348645.html.

Sippel, J. A., S. A. Braun, and C. Shie, 2011: Environmental influences on the strength of Tropical Storm Debby (2006). J. Atmos. Sci., 68, 2557-2581, https://doi.org/10.1175/ 2011JAS3648.1.

Skamarock, W. C., and Coauthors, 2008: A description of the Advanced Research WRF version 3. NCAR Tech. Note NCAR/TN-475+STR, 113 pp., https://doi.org/10.5065/ D68S4MVH.
Skinner, P. S., C. C. Weiss, L. J. Wicker, C. K. Potvin, and D. C. Dowell, 2015: Forcing mechanisms for an internal rear-flank downdraft momentum surge in the 18 May 2010 Dumas, Texas, supercell. Mon. Wea. Rev., 143, 4305-4330, https:// doi.org/10.1175/MWR-D-15-0164.1.

Stoelinga, M. T., J. F. Bresch, P. A. Mooney, J. G. Powers, and K. W. Manning, 2018: Users' guide to RIP version 4.7: A program for visualizing mesoscale model output. UCAR, accessed 3 December 2018, http://www2.mmm.ucar.edu/wrf/ users/docs/ripug.htm.

Trier, S. B., J. H. Marsham, C. A. Davis, and D. A. Ahijevych, 2011: Numerical simulations of the postsunrise reorganization of a nocturnal mesoscale convective system during 13 June IHOP_2002. J. Atmos. Sci., 68, 2988-3011, https://doi.org/ 10.1175/JAS-D-11-0112.1.

Verlinde, J., and W. R. Cotton, 1993: Fitting microphysical observations of nonsteady convective clouds to a numerical model: An application of the adjoint technique of data assimilation to a kinematic model. Mon. Wea. Rev., 121, 2776-2793, https://doi.org/ 10.1175/1520-0493(1993)121<2776:FMOONC>2.0.CO;2.

Warren, R. A., H. Richter, H. A. Ramsay, S. T. Siems, and M. J. Manton, 2017: Impact of variations in upper-level shear on simulated supercells. Mon. Wea. Rev., 145, 2659-2681, https:// doi.org/10.1175/MWR-D-16-0412.1.

Weisman, M. L., and J. B. Klemp, 1982: The dependence of numerically simulated convective storms on vertical wind shear and buoyancy. Mon. Wea. Rev., 110, 504-520, https://doi.org/ 10.1175/1520-0493(1982)110<0504:TDONSC >2.0.CO;2.

$\longrightarrow$, and - 1984: The structure and classification of numerically simulated convective storms in directionally varying wind shears. Mon. Wea. Rev., 112, 2479-2498, https://doi.org/ 10.1175/1520-0493(1984)112<2479:TSACON >2.0.CO;2.

, and R. Rotunno, 2000: The use of vertical wind shear versus helicity in interpreting supercell dynamics. J. Atmos. Sci., 57, 1452-1472, https://doi.org/10.1175/1520-0469(2000)057<1452: TUOVWS $>2.0 . \mathrm{CO} ; 2$.

Xue, M., K. K. Droegemeier, and V. Wong, 2000: The Advanced Regional Prediction System (ARPS): A multi-scale nonhydrostatic atmospheric simulation and prediction model. Part I: Model dynamics and verification. Meteor. Atmos. Phys., 75, 161-193, https://doi.org/10.1007/s007030070003.

Ziegler, C. L., 1985: Retrieval of thermal and microphysical variables in observed convective storms. Part I: Model development and preliminary testing. J. Atmos. Sci., 42, 1487-1509, https://doi.org/ 10.1175/1520-0469(1985)042<1487:ROTAMV>2.0.CO;2. 